\title{
Synthesis and AT1 affinity evaluation of benzamidophenyl analogs of known AT1 receptor ligands with similar aromatic skeleton
}

\author{
Simona Rapposelli, ${ }^{\text {,* }}$ Serena Cuboni, ${ }^{\mathrm{b}}$ Maria Digiacomo, ${ }^{\mathrm{a}}$ Annalina Lapucci, \\ Maria Letizia Trincavelli, ${ }^{b}$ Tiziano Tuccinardi, ${ }^{a}$ and Aldo Balsamo ${ }^{a}$ \\ ${ }^{a}$ Dipartimento di Scienze Farmaceutiche, Università di Pisa, Via Bonanno 6, 56126 Pisa,Italy \\ ${ }^{b}$ Dipartimento di Psichiatria, Neurobiologia, Farmacologia e Biotecnologie, Università di Pisa, \\ Via Bonanno 6, 56126 Pisa, Italy \\ E-mail: rappsi@farm.unipi.it
}

\begin{abstract}
Taking as model compound the amido-derivative 1 described in the literature from Duncia's group as a good AngII antagonist, we have synthesized a new series of compounds (2-7) in which the principal structural variations reside in the inversion of the amidic sequence between the two phenyl ring and/or in the type of heteroaromatic substituent linked to this portion. The new compounds synthesized were evaluated for their AT1 affinity through binding assays carried out on rat liver membranes using $\left[{ }^{125} \mathrm{I}\right]$ Sar1,Ile8-angiotensin II as radioligand.
\end{abstract}

Keywords: Sartan, AT1 antagonist, binding affinity, benzamidophenyl-derivative

\section{Introduction}

The renin-angiotensin system (RAS) plays a fundamental role in the regulation of blood pressure, electrolyte balance, and endocrine functions related to cardiovascular disease. The RAS is a proteolytic cascade in which angiotensinogen released by the kidney is converted into the inactive decapeptide angiotensin I by renin. In turn, angiotensin I is cleft of the two terminal aminoacids by angiotensin-converting enzyme (ACE) to form the octapeptide angiotensin II (AngII). This peptide exerts many physiological effects ${ }^{1}$ on blood pressure and electrolyte balance and it is directly involved in the contraction of the vascular smooth muscle and in aldosterone secretion. In addition to its well-known biological actions, it also influences renal, hepatic, endocrine and reproductive functions and has specific actions in the CNS. ${ }^{2}$ Recent findings $\mathrm{s}^{3,4}$ indicate the involvement of this peptide also in situations concerning tissue remodeling, such as cardiac hypertrophy and cancer. All these responses are mediated by two distinct subtypes of AngII receptors [type 1 (AT1) and type 2 (AT2)]. In particular, AT1 receptors mediate all of the known effects associated to AngII that constitutes the principal target 
of an effectiveness therapy against the cardiovascular pathology. The AngII effects may be reduced by inhibiting almost partially the enzyme responsible of biosynthesis of AngII or through the interaction with AT1 receptor.

For these reasons, it became important to study the development of antagonists of AngII subtype 1 receptor (AT1 antagonists or sartans) viewed as a new class of antihypertensive used in the treatment of hypertension, ${ }^{5}$ heart failure ${ }^{6}$ and renal diseases. ${ }^{7}$

The first non-peptide AT1 antagonist which represents the prototype of the sartans was losartan. The major active metabolite of losartan, EXP3174, generated by the oxidation of the 5hydroxymethyl group on the imidazole ring, is 10-40 times more potent than losartan itself and is therefore responsible for the majority of its pharmacological activity.

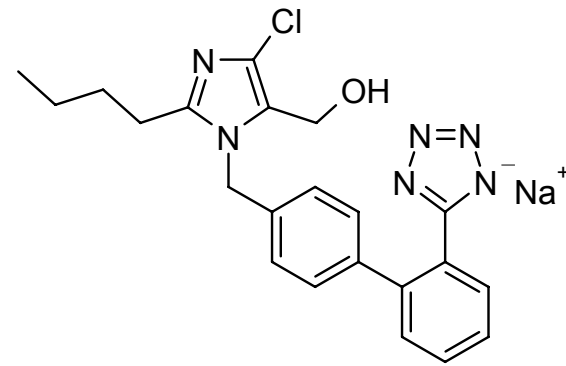

Losartan

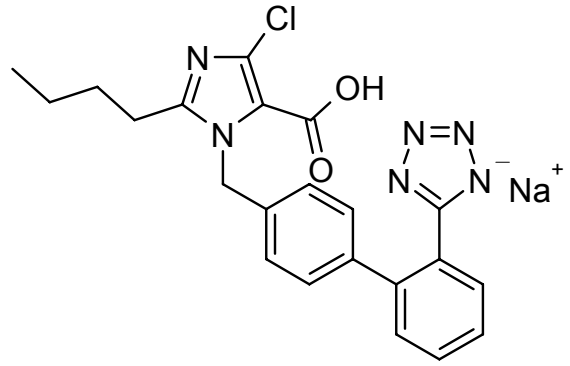

EXP3174

Figure 1. Molecular structures of losartan and its active metabolite (EXP3174).

To date, many orally available sartans have been developed and are used in the treatment of both hypertension and damage associated with diseases like atherosclerosis and diabetes. In particular, the good properties of new non peptide AngII antagonists, such as losartan, have stimulated the design of many different congeners. All these drugs contain some common structural features represented by a biphenyl fragment bearing an acidic moiety (i.e.: tetrazole, carboxylic- or sulphonamidocarboxyl- group), linked to a heteroaromatic or acyclic system by means of a methylene group. Almost all of the chemical manipulations within the fundamental skeleton of sartans, concerned the substitution of the imidazole ring of losartan with several variously substituted heteroaromatic groups or acyclic structures. ${ }^{8}$

The Duncia group reported a series of compounds, ${ }^{9}$ in which, as in the derivative $\mathbf{1}$, the tetrazolyl-substituted biphenyl portion is replaced by a carboxy-substituted benzamido phenyl moiety. Some of the synthesized compounds showed a potent AngII antagonist activity. On this basis, taking as a molecular model the compound 1, we have brought some chemical manipulations to evaluate their effects on the AT1 antagonism in the class of the benzamidophenyl sartans. (figure 2) 

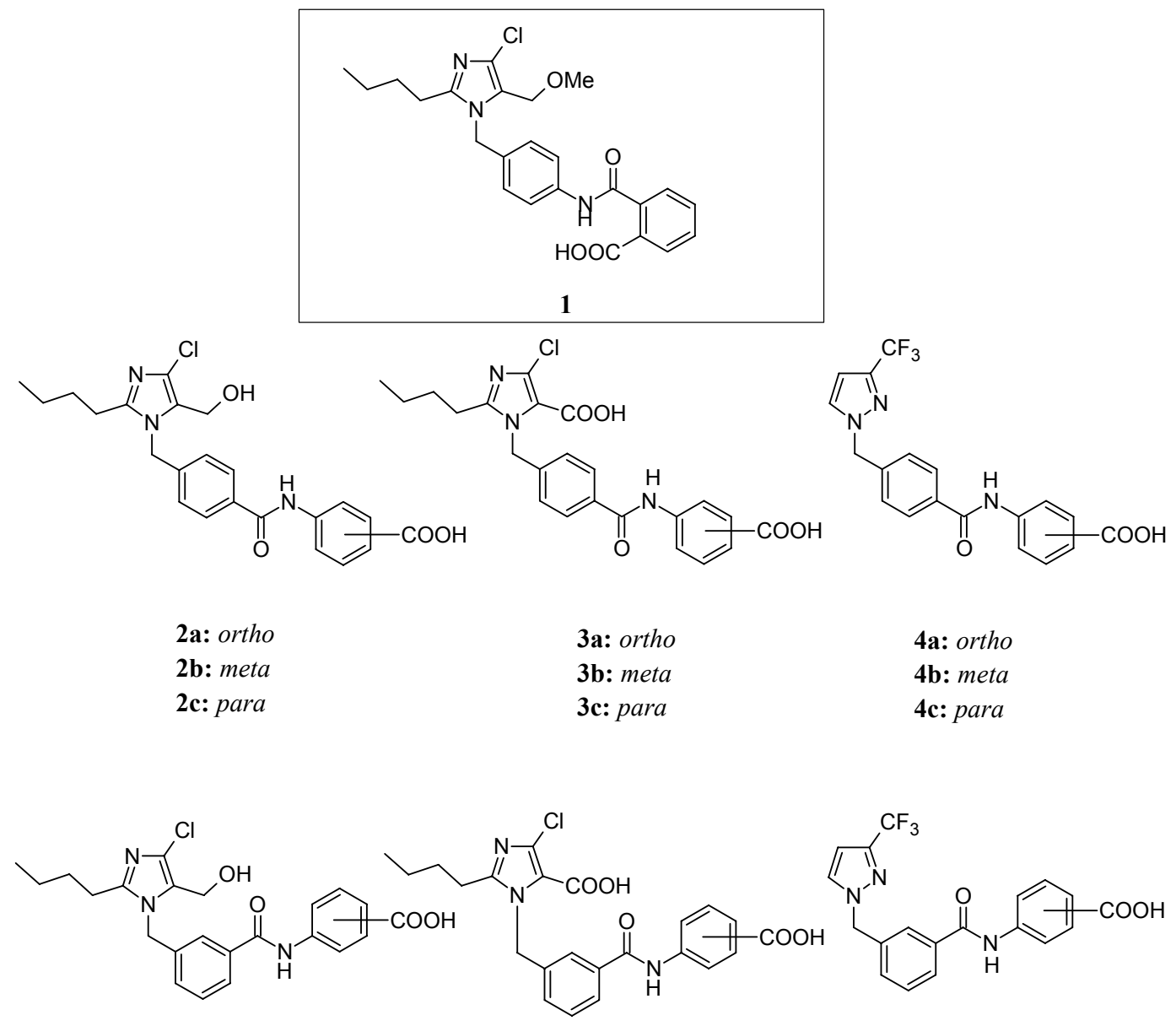

\begin{tabular}{|c|c|c|}
\hline 5a: ortho & 6a: ortho & 7a: ortho \\
\hline 5b: meta & 6b: meta & 7b: meta \\
\hline 5c: para & 6c: para & 7c: para \\
\hline
\end{tabular}

Figure 2. Structures of lead-compound 1 and derivatives 2-7.

The first modification that we carried out, concerned the reversion of the amide bond of the model compound (1) to obtain derivatives $2 \mathbf{a}, \mathbf{3 a}$ in which the methoxymethyl group linked to the 5 position of imidazole (1) is replaced by the hydroxymethyl moiety of losartan (2a), or by the carboxylic function of the active metabolite of losartan (EXP-3174) (3a), respectively. In addition, in order to obtain further information about the steric requisites necessary for a good interaction with AT1 receptor, we have also synthesized the isomers $\mathbf{2 b}, \mathbf{c}$ and $\mathbf{3 b}, \mathbf{c}$ in which the carboxylic function of the benzoic portion is in the meta $(\mathbf{2 b}, \mathbf{3 b})$ and para position $(\mathbf{2 c}, \mathbf{3 c})$.

Compounds 4a-c were successively synthesized in order to evaluate the effect of the replacement of the structurally complex imidazole portion of 2a-c and 3a-c, also present in losartan and in its metabolite EXP3174, with another heterocyclic system such as the pyrazole substituted in 3 position with an electron-withdrawing group (trifluoromethyl) hypothesizing that this substituent may favour the interaction with the AT1 receptor. 
Compounds 5a-c, 6a-c, and 7a-c were also prepared as structural isomers of derivatives $\mathbf{2 a - c}$, 3a-c, and 4a-c respectively, in which the carboxamidobenzoic- group is linked in position 3 of the aromatic ring.

Table 1. Melting points and yields of final products 2-7

\begin{tabular}{cccc}
\hline Compound & Substrate & Mp, ${ }^{\circ} \mathrm{C}$ & Yield, \% \\
\hline $\mathbf{2 a}$ & $\mathrm{C}_{23} \mathrm{H}_{24} \mathrm{ClN}_{3} \mathrm{O}_{4}$ & $150-152$ & 41 \\
$\mathbf{2 b}$ & $\mathrm{C}_{23} \mathrm{H}_{24} \mathrm{ClN}_{3} \mathrm{O}_{4}$ & $170-172$ & 57 \\
$\mathbf{2 c}$ & $\mathrm{C}_{23} \mathrm{H}_{24} \mathrm{ClN}_{3} \mathrm{O}_{4}$ & $180-182$ & 80 \\
$\mathbf{3 a}$ & $\mathrm{C}_{23} \mathrm{H}_{22} \mathrm{ClN}_{3} \mathrm{O}_{5}$ & $191-193$ & 80 \\
$\mathbf{3 b}$ & $\mathrm{C}_{23} \mathrm{H}_{22} \mathrm{ClN}_{3} \mathrm{O}_{5}$ & $122-124$ & 85 \\
$\mathbf{3 c}$ & $\mathrm{C}_{23} \mathrm{H}_{22} \mathrm{ClN}_{3} \mathrm{O}_{5}$ & $135-137$ & 47 \\
$\mathbf{4 a}$ & $\mathrm{C}_{19} \mathrm{H}_{14} \mathrm{~F}_{3} \mathrm{~N}_{3} \mathrm{O}_{3}$ & $145-147$ & 33 \\
$\mathbf{4 b}$ & $\mathrm{C}_{19} \mathrm{H}_{14} \mathrm{~F}_{3} \mathrm{~N}_{3} \mathrm{O}_{3}$ & $190-192$ & 52 \\
$\mathbf{4 c}$ & $\mathrm{C}_{19} \mathrm{H}_{14} \mathrm{~F}_{3} \mathrm{~N}_{3} \mathrm{O}_{3}$ & $>230$ & 75 \\
$\mathbf{5 a}$ & $\mathrm{C}_{23} \mathrm{H}_{24} \mathrm{ClN}_{3} \mathrm{O}_{4}$ & $104-106$ & 90 \\
$\mathbf{5 b}$ & $\mathrm{C}_{23} \mathrm{H}_{24} \mathrm{ClN}_{3} \mathrm{O}_{4}$ & $168-170$ & 40 \\
$\mathbf{5 c}$ & $\mathrm{C}_{23} \mathrm{H}_{24} \mathrm{ClN}_{3} \mathrm{O}_{4}$ & $88-90$ & 55 \\
$\mathbf{6 a}$ & $\mathrm{C}_{23} \mathrm{H}_{22} \mathrm{ClN}_{3} \mathrm{O}_{5}$ & $179-181$ & 79 \\
$\mathbf{6 b}$ & $\mathrm{C}_{23} \mathrm{H}_{22} \mathrm{ClN}_{3} \mathrm{O}_{5}$ & $105-107$ & 52 \\
$\mathbf{6 c}$ & $\mathrm{C}_{23} \mathrm{H}_{22} \mathrm{ClN}_{3} \mathrm{O}_{5}$ & $120-122$ & 55 \\
$\mathbf{7 a}$ & $\mathrm{C}_{19} \mathrm{H}_{14} \mathrm{~F}_{3} \mathrm{~N}_{3} \mathrm{O}_{3}$ & $153-155$ & 61 \\
$\mathbf{7 b}$ & $\mathrm{C}_{19} \mathrm{H}_{14} \mathrm{~F}_{3} \mathrm{~N}_{3} \mathrm{O}_{3}$ & $178-180$ & 44 \\
$\mathbf{7 c}$ & $\mathrm{C}_{19} \mathrm{H}_{14} \mathrm{~F}_{3} \mathrm{~N}_{3} \mathrm{O}_{3}$ & $170-172$ & 42 \\
\hline & & & \\
\hline
\end{tabular}

The 5'-hydroxymethylimidazole derivatives $\mathbf{2 a - c}$ and 5a-c and their analogues carboxylic acids (3a-c and 6a-c) were synthesized according to the procedure reported in Scheme 1. 


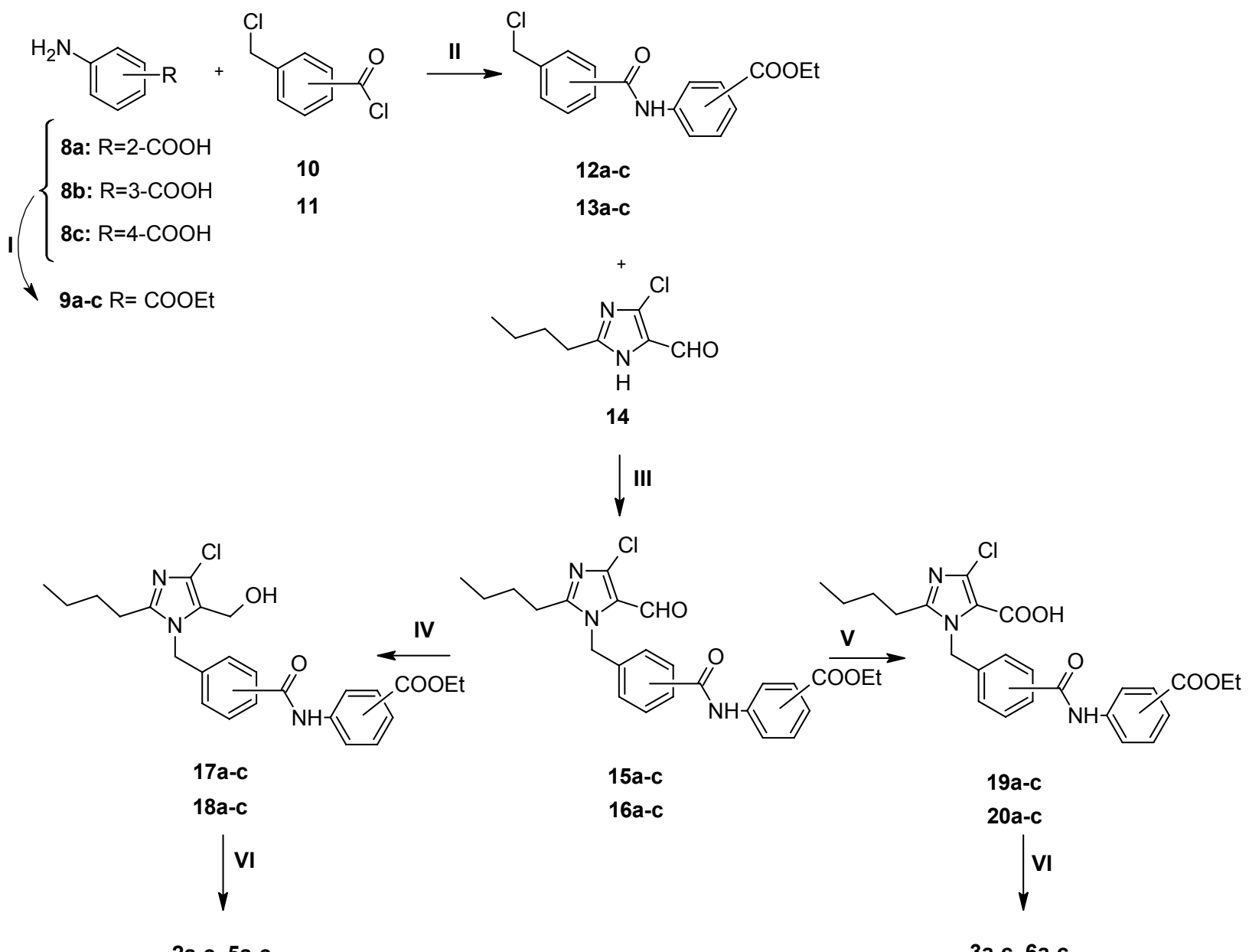

2a-c, 5a-c

3a-c, 6a-c

Scheme 1. Reagents and reaction conditions: I: $\mathrm{SOCl}_{2}$, EtOH, reflux, 48h; II: $\mathrm{Et}_{3} \mathrm{~N}, \mathrm{CH}_{2} \mathrm{Cl}_{2}$, r.t., 20h; III: $\mathrm{K}_{2} \mathrm{CO}_{3}$, DMAC, r.t., 12h; IV: $\mathrm{NaBH}_{4}, \mathrm{MeOH}$, r.t., 1h; V: t-BuOH, $\mathrm{NaClO}_{2}, \mathrm{NaH}_{2} \mathrm{PO}_{4}$, $\mathrm{H}_{2} \mathrm{O}$; VI: $\mathrm{KOH} \mathrm{50 \% ,} \mathrm{MeOH,} \mathrm{reflux,} 2 \mathrm{~h}$.

The reaction of the appropriate (amino)benzoic acid 8a-c with $\mathrm{SOCl}_{2}$ and $\mathrm{EtOH}$ afforded the ethylic esters 9a-c which were subsequently N-alkylated with 4-(chloromethyl)-benzoylchloride (10) or 3-(chloromethyl)benzoylchloride (11) in the presence of a catalytic amount of $\mathrm{NEt}_{3}$ to give the carboxamido-derivatives 12a-c and 13a-c, respectively.

Compounds 15a-c, 16a-c were obtained by a condensation reaction of chloromethylderivatives (12a-c, 13a-c) and the 2-butyl-4-chloro-5-imidazolecarboxaldehyde (14), in the presence of DMAC and $\mathrm{K}_{2} \mathrm{CO}_{3}$.

The intermediates 15a-c and 16a-c were then submitted to reduction with $\mathrm{NaBH}_{4}$ in $\mathrm{MeOH}$ to afford the 5-hydroxymethyl-derivatives 17a-c and 18a-c or to an oxidation with $\mathrm{NaClO}_{2}$ and a buffer solution of $\mathrm{NaH}_{2} \mathrm{PO}_{4}(\mathrm{pH}=4.3)$ to obtain derivatives 19a-c, 20a-c.

The esters 17-20 were refluxed with an aqueous solution of $\mathrm{KOH} 50 \%$ to give the corresponding acids $\mathbf{2 , 3 , 5 , 6}$. 
The key intermediate $\mathbf{1 4}$ was selected to promote the $\mathrm{N}$-alkylation at the nitrogen atom in position 1 rather than in position $3 .^{10}$

Reaction of 3-trifluoromethylpyrazole (21) and chloromethyl-derivatives 12a-c and 13a-c in the presence of $\mathrm{K}_{2} \mathrm{CO}_{3}$ and a catalytic amount of KI afforded the esters 22a-c and 23a-c that were then hydrolysed to the corresponding acids $\mathbf{4 a - c}$ and $7 \mathbf{a}-\mathbf{c}$ following the same procedure described above for the imidazole-derivatives $\mathbf{2 , 3 , 5 , 6}$.(Scheme 2).
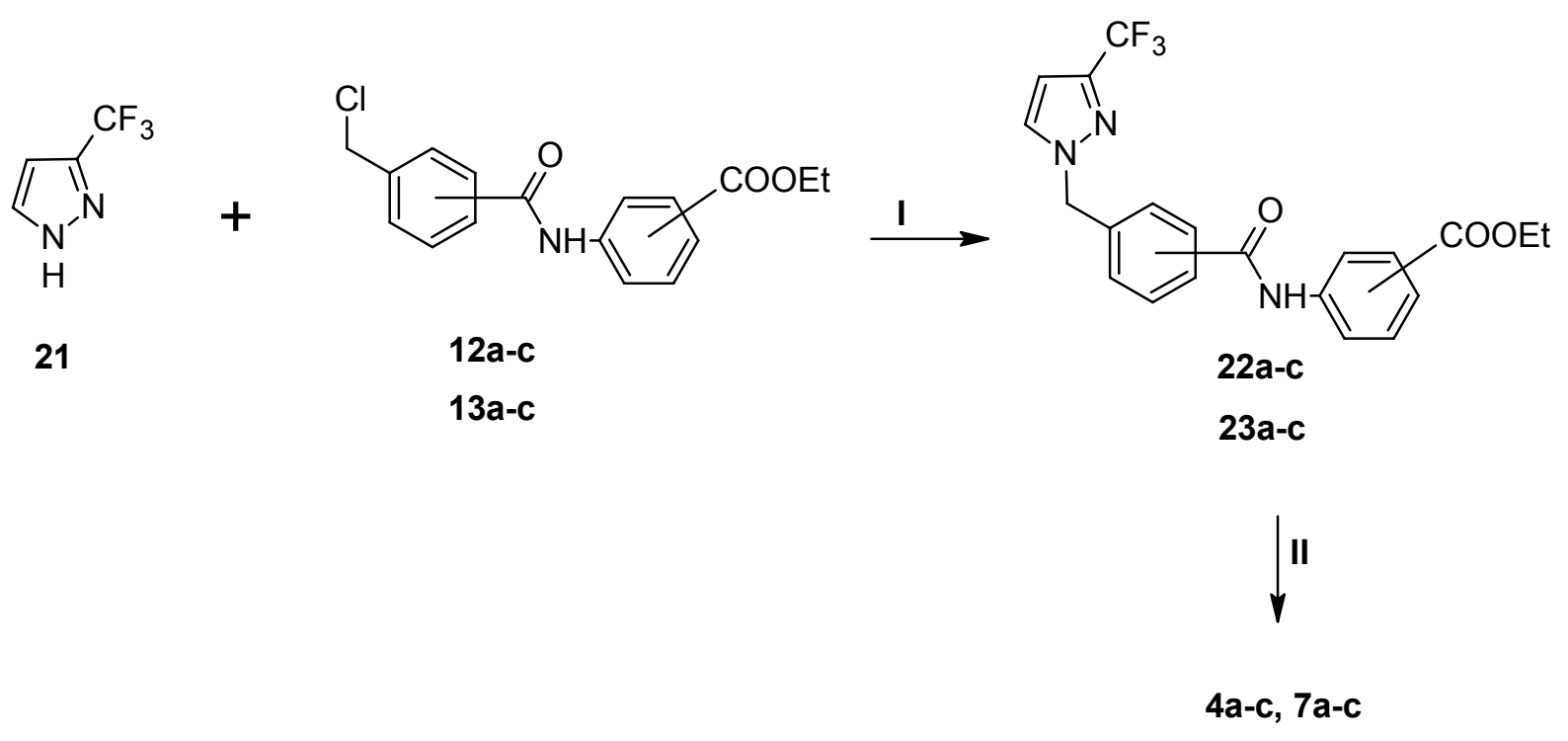

Scheme 2. Reagents and reaction conditions: I: $\mathrm{K}_{2} \mathrm{CO}_{3}, \mathrm{KI}, \mathrm{CH}_{3} \mathrm{CN}$, reflux, 5h; II: $\mathrm{KOH} 50 \%$, $\mathrm{MeOH}$, reflux, 3h.

\section{Results and Discussion}

Compounds 2-7 have been tested for their AT1 affinity through a binding assay carried out on rat liver membrane using $\left[{ }^{125} \mathrm{I}\right] \mathrm{Sar}^{1}, \mathrm{Ile}^{8}$-angiotensina II as radioligand.

In the same tests were also evaluated the AT1 affinities of the ester intermediates (17a,b,c20a,b,c, 22a-c and 23a-c). All synthesized compounds were not active towards AT1 receptor; in particular, only the acid derivatives $5 \mathbf{a}$ and $\mathbf{4 b}, \mathbf{c}$ showed a modest affinity with percentage inhibition values close to $40 \%$ at $10 \mu \mathrm{M}$. As concerns the esters intermediates only compound $19 \mathrm{c}$ showed a percentage inhibition value of $50 \%$.

These results seem to indicate that the simple reversion of the amido-function of modelcompound 1 induced a dramatic loss of affinity towards the AT1 receptor, independently from other molecular variables such as the nature of the substituents on the imidazole nucleus, the position of the amidic junction between the two phenyl rings or the acidic moiety on the benzoic system, or the different type of heterocyclic system (imidazole or pyrazole). 
This negative result may be attributed to different molecular geometries of the new compounds with respect to that of model compound $\mathbf{1}$, because of the reversion of the amidofunction. This simple chemical manipulation may be hindering an optimal fit of the new compounds with the receptor site.

A docking study was carried out in order to explain the experimentally observed low AT1 affinity. For this purpose a previously developed model of the AT1 receptor was used. ${ }^{11}$ Figure 3A shows the docking of compound 1 into the AT1 receptor model, the carboxy-substituted benzamido phenyl moiety of 1 was positioned between TM3, TM6 and TM7, in a lipophilic cavity principally delimited by V3.32(108), V179, W6.48(253), H6.51(256), I7.39(288) and Y7.43(292). The carboxylic function forming an intramolecular H-bond with the nitrogen of the amido group (forming a pseudo-seven member heterocycle), it was directed towards the extracellular side of the receptor, and interacted with T175 and Y184, which are two residues of the second extracellular loop (EL2) and with H6.51(256). As regards the 2'-butyl substituent, it was directed towards TM4, and interacted in a secondary lipophilic pocket created by S3.33(109), L3.36(112), Y3.37(113), A4.60(163), F171 and F182 of EL2, while the hydroxymethyl group formed an $\mathrm{H}$ bond with K5.42(199). Mutagenesis data suggested an important role for V3.32(108), A4.60(163) and K5.42(199), ${ }^{12}$ supporting our binding hypothesis. The reversion of the amido-function of compound 1 induced the loss of affinity towards AT1 receptor. Figure 3B shows the docking of compound 5a: the inversion of the amido-function determined the formation of a six member pseudocycle and an overturning of the disposition of the carboxylic group, directed towards the intracellular side of the receptor. This binding disposition determined the loss of the electrostatic interactions of the carboxylic group with T175, Y184 and H6.51(256), thus explaining its lower affinity.
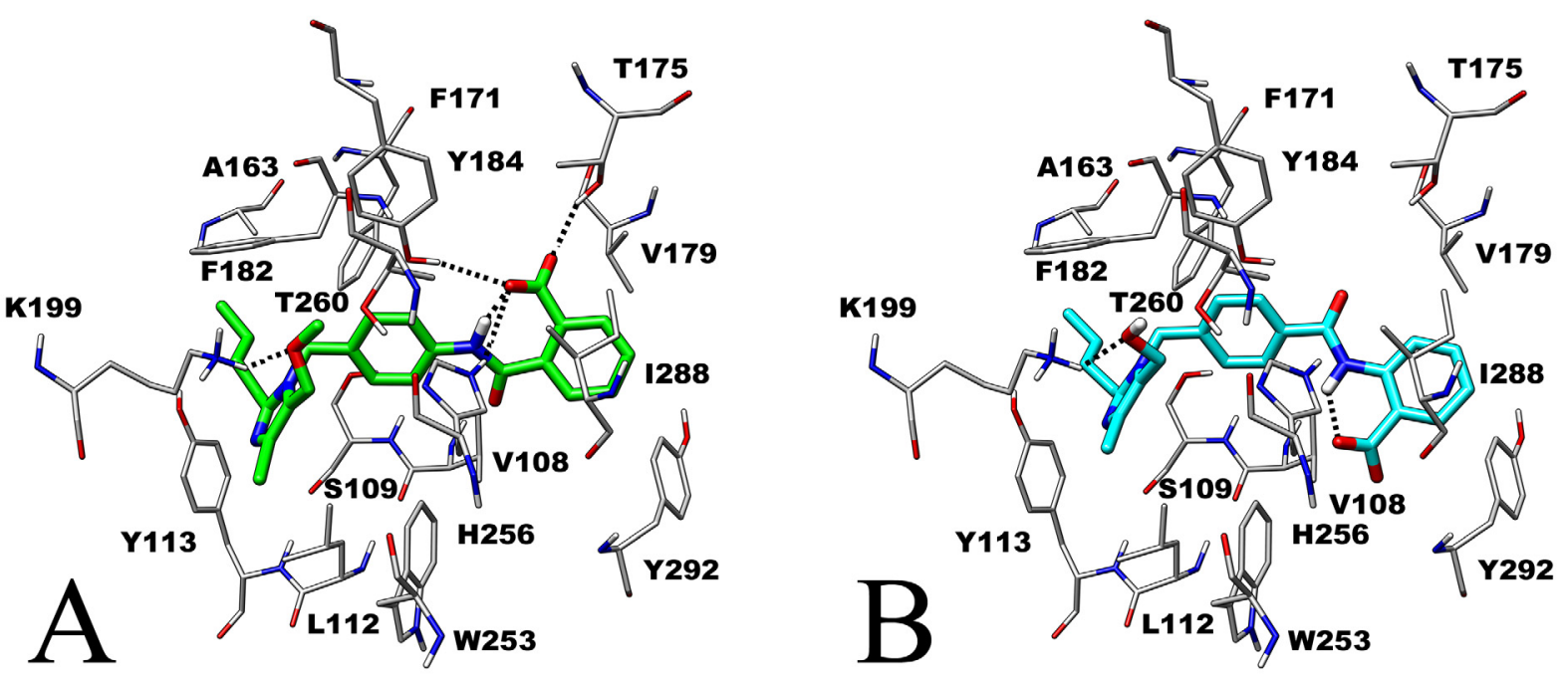

Figure 3. Compound $\mathbf{1}$ (on the left) and $\mathbf{5 a}$ (on the right) docked in the AT1 binding site. 


\section{Experimental Section}

General Procedures. Melting points were determined on a Kofler hot-stage apparatus and are uncorrected. IR spectra were taken as paraffin oil mulls or as liquid films on a Nicolet/Avatar, 360FT. NMR spectra were obtained with a Varian Gemini $200 \mathrm{MHz}$ spectrometer. Chemical shifts $(\delta)$ are reported in parts per million downfield from tetramethylsilane and referenced from solvent references. Mass spectra were obtained on a Hewlett-Packard 5988 A spectrometer using a direct injection probe and an electron beam energy of $70 \mathrm{eV}$. The elemental compositions of the compounds agreed to within $\pm 0.4 \%$ of the calculated value. Chromatographic separation was performed on silica gel columns by flash (Kieselgel 40, 0.040-0.063 mm; Merck) or gravity column (Kieselgel 60, 0.063-0.200 mm; Merck) chromatography. Reactions were followed by thin-layer chromatography (TLC) on Merck aluminum silica gel $\left(60 \mathrm{~F}_{254}\right)$ sheets that were visualised under a UV lamp. Evaporation was performed in vacuo (rotating evaporator). Sodium sulfate was always used as the drying agent. Commercially available chemicals were purchased from Sigma-Aldrich.

\section{General procedure for preparation of compounds $2 a, b, c-7 a, b, c$}

To a solution of the corresponding ester 17a,b,c-20a,b,c, 22a-c, 23a-c $(0.76 \mathrm{mmol})$ in $\mathrm{MeOH}$ $(2.8 \mathrm{~mL})$ was added dropwise an aqueous solution of $\mathrm{KOH} 50 \%(0.13 \mathrm{~mL})$. The resulting solution was refluxed for $2 \mathrm{~h}$, then, after cooling, the solvent was evaporated. The residue was acidified to $\mathrm{pH} 3$ with $\mathrm{HCl} 1 \mathrm{~N}$ and the aqueous phase was extracted with AcOEt. The organic phase was dried and the solvent was evaporated. The crude product was purified by crystallization from AcOEt/hexane to give $\mathbf{2 a}, \mathbf{b}, \mathbf{c}-\mathbf{7 a}, \mathbf{b}, \mathbf{c}$.

2-[(4-\{[4-Chloro-2-butyl-5-(hydroxymethyl)-1 $\boldsymbol{H}$-imidazolyl]methyl\}benzoyl)amino]benzoic acid (2a). (138 mg, $0.31 \mathrm{mmol}$, yield $41 \%$ ): ${ }^{1} \mathrm{H}$ NMR (DMSO- $\left.d_{6}\right) \delta 0.78(\mathrm{t}, 3 \mathrm{H}, J=7.1 \mathrm{~Hz}$, $\left.\mathrm{CH}_{3}\right) ; 1.09-1.28\left(\mathrm{~m}, 2 \mathrm{H}, \mathrm{CH}_{2}\right) ; 1.39-1.50\left(\mathrm{~m}, 2 \mathrm{H}, \mathrm{CH}_{2}\right) ; 2.36-2.48\left(\mathrm{~m}, 2 \mathrm{H}, \mathrm{CH}_{2}\right) ; 4.35(\mathrm{~s}, 2 \mathrm{H}$, $\mathrm{CH}_{2} \mathrm{OH}$ ); 5.37 (s, $\left.2 \mathrm{H}, \mathrm{CH}_{2} \mathrm{~N}\right) ; 7.18-7.23$ (m, $\left.1 \mathrm{H}, \mathrm{Ar}\right) ; 7.27$ (d, $2 \mathrm{H}, J=7.9 \mathrm{~Hz}, \mathrm{AA}^{\prime} X^{\prime}$ '); $7.63-$ 7.07 (m, 1H, Ar); 7.93 (d, 2H, $J=7.9 \mathrm{~Hz}, \mathrm{AA}^{\prime} \mathrm{XX}^{\prime}$ ); 8.05 (d, 1H, $J=8.1 \mathrm{~Hz}, \mathrm{Ar}$ ); 8.69 (d, 1H, $J$ $=8.1 \mathrm{~Hz}, \mathrm{Ar}) ; 12.13 \mathrm{ppm}(\mathrm{br} \mathrm{s}, 1 \mathrm{H})$. MS $m / z: 442\left(\mathrm{M}^{+}, 3\right)$. Anal. Calcd for $\mathrm{C}_{23} \mathrm{H}_{24} \mathrm{ClN}_{3} \mathrm{O}_{4}: \mathrm{C}$ 62.52; H 5.44; N 9.51; Found: C 62.59; H 5.07; N 9.16.

3-[(4-\{[4-Chloro-2-butyl-5-(hydroxymethyl)-1H-imidazolyl]methyl\}benzoyl)amino]benzoic acid (2b). (191 mg, $0.43 \mathrm{mmol}$, yield $57 \%$ ): ${ }^{1} \mathrm{H} \mathrm{NMR}\left(\mathrm{CD}_{3} \mathrm{COCD}_{3}\right) \delta 0.83(\mathrm{t}, 3 \mathrm{H}, J=7.2 \mathrm{~Hz}$, $\left.\mathrm{CH}_{3}\right) ; 1.19-1.36\left(\mathrm{~m}, 2 \mathrm{H}, \mathrm{CH}_{2}\right) ; 1.52-1.67\left(\mathrm{~m}, 2 \mathrm{H}, \mathrm{CH}_{2}\right) ; 2.58\left(\mathrm{t}, 2 \mathrm{H}, J=7.8 \mathrm{~Hz}, \mathrm{CH}_{2}\right) ; 4.51(\mathrm{~s}$, $\left.2 \mathrm{H}, \mathrm{CH}_{2} \mathrm{OH}\right) ; 5.45\left(\mathrm{~s}, 2 \mathrm{H}, \mathrm{CH}_{2} \mathrm{~N}\right) ; 7.27$ (d, 2H, $\left.J=7.8 \mathrm{~Hz}, \mathrm{AA}^{\prime} \mathrm{XX}^{\prime}\right) ; 7.45-7.53$ (m, 2H, Ar); 7.79 (d, $1 \mathrm{H}, J=7.5 \mathrm{~Hz}, \mathrm{Ar}) ; 8.02$ (d, 2H, $\left.J=7.8 \mathrm{~Hz}, \mathrm{AA}^{\prime} \mathrm{XX}^{\prime}\right) ; 8.15$ (d, $1 \mathrm{H}, J=8.2 \mathrm{~Hz}, \mathrm{Ar}$ ); 8.49 (br s, $1 \mathrm{H}$ ); $9.72 \mathrm{ppm}$ (br s, $1 \mathrm{H}$ ). $\mathrm{MS} m / z: 442\left(\mathrm{M}^{+}, 4\right)$. Anal. Calcd for $\mathrm{C}_{23} \mathrm{H}_{24} \mathrm{ClN}_{3} \mathrm{O}_{4}: \mathrm{C}$ 62.52; H 5.44; N 9.51; Found: C 62.54; H 5.16; N 9.09.

4-[(4-\{[4-Chloro-2-butyl-5-(hydroxymethyl)-1 $\mathrm{H}$-imidazolyl]methyl\}benzoyl)amino]benzoic acid (2c). (269 mg, $0.61 \mathrm{mmol}$, yield $80 \%$ ): IR: $1685\left(\mathrm{C}=\mathrm{O}\right.$ of acid), $1640\left(\mathrm{C}=\mathrm{O}\right.$ of amide) $\mathrm{cm}^{-1}$. ${ }^{1} \mathrm{H}$ NMR $\left(\mathrm{CD}_{3} \mathrm{COCD}_{3}\right) \delta 0.83\left(\mathrm{t}, 3 \mathrm{H}, J=7.1 \mathrm{~Hz}, \mathrm{CH}_{3}\right) ; 1.28-1.36\left(\mathrm{~m}, 2 \mathrm{H}, \mathrm{CH}_{2}\right) ; 1.55-1.63(\mathrm{~m}$, 
$\left.2 \mathrm{H}, \mathrm{CH}_{2}\right) ; 2.55\left(\mathrm{t}, 2 \mathrm{H}, J=7.5 \mathrm{~Hz}, \mathrm{CH}_{2}\right) ; 4.51\left(\mathrm{~s}, 2 \mathrm{H}, \mathrm{CH}_{2} \mathrm{OH}\right) ; 5.44\left(\mathrm{~s}, 2 \mathrm{H}, \mathrm{CH}_{2} \mathrm{~N}\right) ; 7.26(\mathrm{~d}, 2 \mathrm{H}$, $J=8.1 \mathrm{~Hz}, \mathrm{Ar}) ; 7.94-8.02$ (m, $6 \mathrm{H}, \mathrm{Ar}) ; 9.81 \mathrm{ppm}(\mathrm{br} \mathrm{s}, 1 \mathrm{H}) .{ }^{13} \mathrm{C} \mathrm{NMR}\left(\mathrm{CD}_{3} \mathrm{COCD}_{3}\right): \delta 167.18$; $166.20 ; 148.70 ; 144.46 ; 142.15 ; 137.47 ; 135.30 ; 131.39 ; 128.96 ; 127.29 ; 126.56 ; 122.92$; $120.30 ; 53.24 ; 47.90 ; 30.37 ; 27.22 ; 22.96 ; 14.02$. MS $m / z: 442\left(\mathrm{M}^{+}, 10\right)$. Anal. Calcd for $\mathrm{C}_{23} \mathrm{H}_{24} \mathrm{ClN}_{3} \mathrm{O}_{4}$ : C 62.52; H 5.44; N 9.51; Found: $\mathrm{C} 62.52 ; \mathrm{H} 5.44 ; \mathrm{N} 9.51$.

2-\{[4-[(4-Chloro-2-butyl-5-carboxy-1 $\boldsymbol{H}$-imidazolyl)methyl]benzoyl]amino $\}$ benzoic acid $\left(3^{\mathbf{a}}\right)$. (277 mg, $0.61 \mathrm{mmol}$, yield $80 \%$ ): ${ }^{1} \mathrm{H}$ NMR (DMSO- $\left.d_{6}\right) \delta 0.80\left(\mathrm{t}, 3 \mathrm{H}, J=7.1 \mathrm{~Hz}, \mathrm{CH}_{3}\right.$ ); $1.20-$ $1.31\left(\mathrm{~m}, 2 \mathrm{H}, \mathrm{CH}_{2}\right) ; 1.49-1.57\left(\mathrm{~m}, 2 \mathrm{H}, \mathrm{CH}_{2}\right) ; 2.61\left(\mathrm{~d}, 2 \mathrm{H}, J=7.4 \mathrm{~Hz}, \mathrm{CH}_{2}\right) ; 5.67\left(\mathrm{~s}, 2 \mathrm{H}, \mathrm{CH}_{2} \mathrm{~N}\right)$; 7.17-7.24 (m, 3H, Ar); 7.62-7.70 (m, 1H, Ar); 7.91 (d, $2 \mathrm{H}, J=7.3 \mathrm{~Hz}, \mathrm{Ar}) ; 8.05$ (d, $1 \mathrm{H}, J=7.6$ $\mathrm{Hz}, \mathrm{Ar}) ; 8.67$ (d, $1 \mathrm{H}, J=8.4 \mathrm{~Hz}, \mathrm{Ar}) ; 12.13 \mathrm{ppm}$ (br s, $1 \mathrm{H})$. MS m/z: $441\left(\mathrm{M}^{+}, 8\right)$. Anal. Calcd for $\mathrm{C}_{23} \mathrm{H}_{22} \mathrm{ClN}_{3} \mathrm{O}_{5}$ : C 60.60; H 4.83; N 9.22; Found: $\mathrm{C} 60.59 ; \mathrm{H} 4.48 ; \mathrm{N} 9.11$.

3-\{[4-[(4-Chloro-2-butyl-5-carboxy-1H-imidazolyl)methyl]benzoyl]amino\}benzoic acid (3b). (294 mg, $0.65 \mathrm{mmol}$, yield $85 \%$ ): IR: $1690\left(\mathrm{C}=\mathrm{O}\right.$ of acid), $1641(\mathrm{C}=\mathrm{O}$ of amide $) \mathrm{cm}^{-1} .{ }^{1} \mathrm{H}$ NMR (DMSO- $\left.d_{6}\right) \delta 0.82\left(\mathrm{t}, 3 \mathrm{H}, J=7.1 \mathrm{~Hz}, \mathrm{CH}_{3}\right) ; 1.22-1.33\left(\mathrm{~m}, 2 \mathrm{H}, \mathrm{CH}_{2}\right) ; 1.48-1.59(\mathrm{~m}, 2 \mathrm{H}$, $\left.\mathrm{CH}_{2}\right) ; 2.61\left(\mathrm{~d}, 2 \mathrm{H}, J=7.5 \mathrm{~Hz}, \mathrm{CH}_{2}\right) ; 5.68\left(\mathrm{~s}, 2 \mathrm{H}, \mathrm{CH}_{2} \mathrm{~N}\right) ; 7.14$ (d, $\left.2 \mathrm{H}, J=8.0 \mathrm{~Hz}, \mathrm{AA}^{\prime} \mathrm{XX}^{\prime}\right)$; 7.42-7.51 (m, 2H, Ar); 7.67 (d, 1H, $J=7.5 \mathrm{~Hz}, \mathrm{Ar}$ ); 7.93 (d, 2H, $\left.J=8.0 \mathrm{~Hz}, \mathrm{AA}^{\prime} X X^{\prime}\right) ; 7.90-8.10$ (m, $1 \mathrm{H}, \mathrm{Ar}) ; 8.39$ (br s, $1 \mathrm{H}) ; 12.13 \mathrm{ppm}(\mathrm{br} \mathrm{s}, 1 \mathrm{H}) .{ }^{13} \mathrm{C} \mathrm{NMR}\left(\mathrm{CD}_{3} \mathrm{COCD}_{3}\right): \delta 167.30 ; 166.05$; $160.81 ; 153.25 ; 150.81 ; 140.44 ; 138.07 ; 132.90 ; 132.00 ; 129.62 ; 128.87 ; 127.05 ; 125.69$; $125.29 ; 124.21 ; 122.21 ; 49.03 ; 30.00 ; 27.29 ; 22.92 ; 13.98$. MS $m / z: 441\left(\mathrm{M}^{+}, 20\right)$. Anal. Calcd for $\mathrm{C}_{23} \mathrm{H}_{22} \mathrm{ClN}_{3} \mathrm{O}_{5}$ : C 60.60; $\mathrm{H} 4.83$; $\mathrm{N} 9.22$; Found: $\mathrm{C} 60.31 ; \mathrm{H} 4.90 ; \mathrm{N} 9.35$.

4-\{[4-[(4-Chloro-2-butyl-5-carboxy-1 $\boldsymbol{H}$-imidazolyl)methyl]benzoyl]amino\}benzoic acid (3c). (90 mg, $0.20 \mathrm{mmol}$, yield $47 \%$ ): ${ }^{1} \mathrm{H}$ NMR (DMSO- $\left.d_{6}\right) \delta 0.81\left(\mathrm{t}, 3 \mathrm{H}, J=7.1 \mathrm{~Hz}, \mathrm{CH}_{3}\right) ; 1.20-1.33$ (m, 2H, $\left.\mathrm{CH}_{2}\right) ; 1.48-1.59\left(\mathrm{~m}, 2 \mathrm{H}, \mathrm{CH}_{2}\right) ; 2.61\left(\mathrm{~d}, 2 \mathrm{H}, J=7.2 \mathrm{~Hz}, \mathrm{CH}_{2}\right) ; 5.67\left(\mathrm{~s}, 2 \mathrm{H}, \mathrm{CH}_{2} \mathrm{~N}\right) ; 7.14$ (d, $2 \mathrm{H}, J=8.2 \mathrm{~Hz}, \mathrm{AA}^{\prime} \mathrm{XX}$ ); 7.80-8.00 (m, 6H, Ar); $10.52 \mathrm{ppm}$ (br s, 1H). MS m/z: 441 $\left(\mathrm{M}^{+}, 19\right)$. Anal. Calcd for $\mathrm{C}_{23} \mathrm{H}_{22} \mathrm{ClN}_{3} \mathrm{O}_{5}$ : $\mathrm{C} 60.60 ; \mathrm{H} \mathrm{4.83;} \mathrm{N} \mathrm{9.22;} \mathrm{Found:} \mathrm{C} 60.78 ; \mathrm{H} 4.52 ; \mathrm{N}$ 9.40 .

2-[(4-\{[3-(Trifluoromethyl)-1 $\boldsymbol{H}$-pyrazolyl]methyl\}benzoyl)amino]benzoic acid (4a). (97 $\mathrm{mg}$, $0.25 \mathrm{mmol}$, yield $33 \%):{ }^{1} \mathrm{H}$ NMR $\left(\mathrm{CD}_{3} \mathrm{COCD}_{3}\right) \delta 5.60\left(\mathrm{~s}, 2 \mathrm{H}, \mathrm{CH}_{2} \mathrm{~N}\right) ; 6.70-6.72(\mathrm{~m}, 1 \mathrm{H}$, pyrazole); 7.16-7.26 (m, 1H, Ar); 7.49-7.74 (m, 4H, Ar, pyrazole); 7.98-8.06 (m, 2H, Ar); 8.18 (d, $1 \mathrm{H}, J=8.1 \mathrm{~Hz}, \mathrm{Ar}) ; 8.90-9.00$ (m, 1H, Ar); $12.13 \mathrm{ppm}$ (br s, 1H). MS m/z: 389 (M+, 3). Anal. Calcd for $\mathrm{C}_{19} \mathrm{H}_{14} \mathrm{~F}_{3} \mathrm{~N}_{3} \mathrm{O}_{3}$ : C 58.61; H 3.50; N 10.79; Found: C 58.25; H 3.15; N 10.48.

3-[(4-\{[3-(Trifluoromethyl)-1H-pyrazolyl]methyl\}benzoyl)amino]benzoic acid (4b). (152 mg, 0.39 mmol, yield $52 \%$ ): IR: $1700\left(\mathrm{C}=\mathrm{O}\right.$ of acid), $1641(\mathrm{C}=\mathrm{O}$ of amide $) \mathrm{cm}^{-1} .{ }^{1} \mathrm{H}$ NMR $\left(\mathrm{CD}_{3} \mathrm{COCD}_{3}\right) \delta 5.58\left(\mathrm{~s}, 2 \mathrm{H}, \mathrm{CH}_{2} \mathrm{~N}\right) ; 6.70-6.72(\mathrm{~m}, 1 \mathrm{H}$, pyrazole); 7.44-7.54 (m, 3H, Ar); 7.777.81 (m, 1H, Ar); 8.00-8.04 (m, 3H, Ar, pyrazole); 8.13-8.18 (m, 2H, Ar); 8.51 (br s, 1H); 9.71 ppm (br s, $1 \mathrm{H}) .{ }^{13} \mathrm{C}$ NMR $\left(\mathrm{CD}_{3} \mathrm{COCD}_{3}\right): \delta 167.42 ; 166.10 ; 143.71 ; 141.00 ; 132.97 ; 132.11$; $129.64 ; 128.87 ; 128.76 ; 128.05 ; 125.72 ; 125.34 ; 123.90 ; 123.67 ; 122.26 ; 105.31 ; 56.55$. MS $m / z: 389\left(\mathrm{M}^{+}, 5\right)$. Anal. Calcd for $\mathrm{C}_{19} \mathrm{H}_{14} \mathrm{~F}_{3} \mathrm{~N}_{3} \mathrm{O}_{3}$ : C 58.61; H 3.50; N 10.79; Found: C 59.00; $\mathrm{H}$ $3.87 ; \mathrm{N} 10.65$. 
4-[(4-\{[3-(Trifluoromethyl)-1H-pyrazolyl]methyl\}benzoyl)amino]benzoic acid (4c). (222 mg, $0.57 \mathrm{mmol}$, yield $75 \%):{ }^{1} \mathrm{H}$ NMR $\left(\mathrm{CD}_{3} \mathrm{COCD}_{3}\right) \delta 5.58\left(\mathrm{~s}, 2 \mathrm{H}, \mathrm{CH}_{2} \mathrm{~N}\right) ; 6.69-6.71(\mathrm{~m}, 1 \mathrm{H}$, pyrazole); 7.76 (d, 2H, $J=8.2 \mathrm{~Hz}, \mathrm{Ar}) ; 7.95-8.06$ (m, 7H, Ar, pyrazole); 9.80 ppm (br s, 1H). MS m/z: $389\left(\mathrm{M}^{+}, 10\right)$. Anal. Calcd for $\mathrm{C}_{19} \mathrm{H}_{14} \mathrm{~F}_{3} \mathrm{~N}_{3} \mathrm{O}_{3}$ : C 58.61; H 3.50; N 10.79; Found: C 58.73; H 3.72; N 10.58 .

2-[(3-\{[4-Chloro-2-butyl-5-(hydroxymethyl)-1H-imidazolyl]methyl\}benzoyl)amino]benzoic acid (5a). (302 mg, $0.68 \mathrm{mmol}$, yield $90 \%):{ }^{1} \mathrm{H} \mathrm{NMR}\left(\mathrm{CD}_{3} \mathrm{COCD}_{3}\right) \delta 0.81(\mathrm{t}, 3 \mathrm{H}, J=7.1 \mathrm{~Hz}$, $\left.\mathrm{CH}_{3}\right)$; 1.19-1.39 (m, 2H, $\left.\mathrm{CH}_{2}\right)$; 1.51-1.66 (m, 2H, $\left.\mathrm{CH}_{2}\right) ; 2.61\left(\mathrm{~d}, 2 \mathrm{H}, J=7.1 \mathrm{~Hz}, \mathrm{CH}_{2}\right) ; 4.54$ (s, $\left.2 \mathrm{H}, \mathrm{CH}_{2} \mathrm{OH}\right) ; 5.47\left(\mathrm{~s}, 2 \mathrm{H}, \mathrm{CH}_{2} \mathrm{~N}\right) ; 7.21$ (t, $\left.1 \mathrm{H}, J=8.0 \mathrm{~Hz}, \mathrm{Ar}\right) ; 7.38$ (d, $\left.1 \mathrm{H}, J=8.0 \mathrm{~Hz}, \mathrm{Ar}\right)$; 7.54-7.71 (m, 2H, Ar); 7.79 (s, 1H, Ar); 7.93 (d, 1H, J=7.2 Hz, Ar); 8.18 (d, 1H, J=8.0 Hz, Ar); 8.88-8.93 (m, 1H, Ar); $12.29 \mathrm{ppm}$ (br s, 1H). MS m/z: $441\left(\mathrm{M}^{+}, 3\right)$. Anal. Calcd for $\mathrm{C}_{23} \mathrm{H}_{24} \mathrm{ClN}_{3} \mathrm{O}_{4}$ : C 62.52; H 5.44; N 9.51; Found: C 62.59; H 5.07; N 9.16.

3-[(3-\{[4-Chloro-2-butyl-5-(hydroxymethyl)-1H-imidazolyl]methyl\}benzoyl)amino]benzoic acid (5b). (134 mg, $0.30 \mathrm{mmol}$, yield $40 \%$ ): ${ }^{1} \mathrm{H}$ NMR (DMSO- $\left.d_{6}\right) \delta 0.78(\mathrm{t}, 3 \mathrm{H}, J=7.3 \mathrm{~Hz}$, $\left.\mathrm{CH}_{3}\right)$; 1.14-1.29 (m, 2H, $\left.\mathrm{CH}_{2}\right)$; 1.39-1.49 (m, 2H, $\left.\mathrm{CH}_{2}\right) ; 2.45-2.51\left(\mathrm{~m}, 2 \mathrm{H}, \mathrm{CH}_{2}\right) ; 4.34(\mathrm{~s}, 2 \mathrm{H}$, $\left.\mathrm{CH}_{2} \mathrm{OH}\right) ; 5.35\left(\mathrm{~s}, 2 \mathrm{H}, \mathrm{CH}_{2} \mathrm{~N}\right) ; 7.21(\mathrm{~d}, 1 \mathrm{H}, J=8.2 \mathrm{~Hz}, \mathrm{Ar}) ; 7.44-7.55(\mathrm{~m}, 2 \mathrm{H}, \mathrm{Ar}) ; 7.66-7.74(\mathrm{~m}$, 2H, Ar); 7.91 (d, 1H, $J=7.5 \mathrm{~Hz}, \mathrm{Ar}) ; 8.02$ (d, 1H, $J=7.7 \mathrm{~Hz}, \mathrm{Ar}) ; 8.39$ (s, 1H, Ar); 10.45 ppm (br s, $1 \mathrm{H}, \mathrm{NH}$ ). $\mathrm{MS} m / z$ : $441\left(\mathrm{M}^{+}, 6\right)$. Anal. Calcd for $\mathrm{C}_{23} \mathrm{H}_{24} \mathrm{ClN}_{3} \mathrm{O}_{4}$ : C 62.52; H 5.44; N 9.51; Found: C 62.54; H 5.16; N 9.09.

4-[(3-\{[4-Chloro-2-butyl-5-(hydroxymethyl)-1H-imidazolyl]methyl\}benzoyl)amino]benzoic acid (5c). (185 mg, $0.42 \mathrm{mmol}$, yield $55 \%$ ): IR: 1702 (C=O of acid), 1648 (C=O of amide) $\mathrm{cm}^{-1}$. ${ }^{1} \mathrm{H}$ NMR $\left(\mathrm{DMSO}-d_{6}\right) \delta 0.78\left(\mathrm{t}, 3 \mathrm{H}, J=7.1 \mathrm{~Hz}, \mathrm{CH}_{3}\right) ; 1.14-1.29\left(\mathrm{~m}, 2 \mathrm{H}, \mathrm{CH}_{2}\right) ; 1.39-1.50(\mathrm{~m}, 2 \mathrm{H}$, $\left.\mathrm{CH}_{2}\right) ; 2.38-2.46\left(\mathrm{~m}, 2 \mathrm{H}, \mathrm{CH}_{2}\right) ; 4.34\left(\mathrm{~s}, 2 \mathrm{H}, \mathrm{CH}_{2} \mathrm{OH}\right) ; 5.35\left(\mathrm{~s}, 2 \mathrm{H}, \mathrm{CH}_{2} \mathrm{~N}\right) ; 7.22(\mathrm{~d}, 1 \mathrm{H}, J=7.5$ $\mathrm{Hz}, \mathrm{Ar}) ; 7.52$ (t, 1H, $J=7.5 \mathrm{~Hz}, \mathrm{Ar}) ; 7.72$ (s, 1H, Ar); 7.87-7.96 (m, 5H, Ar); 10.55 ppm (br s, $1 \mathrm{H}, \mathrm{NH}) .{ }^{13} \mathrm{C} \mathrm{NMR}\left(\mathrm{CD}_{3} \mathrm{COCD}_{3}\right): \delta 167.29 ; 166.31 ; 148.78 ; 144.31 ; 141.49 ; 138.65 ; 136.43 ;$ $132.59 ; 131.37 ; 130.42 ; 129.78 ; 127.44 ; 126.93 ; 126.54 ; 120.30 ; 53.15 ; 47.94 ; 30.35 ; 27.14 ;$ 22.90; 14.02. MS m/z: $441\left(\mathrm{M}^{+}, 25\right)$. Anal. Calcd for $\mathrm{C}_{23} \mathrm{H}_{24} \mathrm{ClN}_{3} \mathrm{O}_{4}: \mathrm{C} 62.52 ; \mathrm{H}$ 5.44; N 9.51; Found: C 62.52; H 5.44; N 9.51.

2-\{[3-[(4-Chloro-2-butyl-5-carboxy-1H-imidazolyl)methyl]benzoyl]amino\}benzoic acid (6a). (273 mg, $0.60 \mathrm{mmol}$, yield $79 \%$ ): ${ }^{1} \mathrm{H}$ NMR (DMSO-d $) \delta 0.79\left(\mathrm{t}, 3 \mathrm{H}, J=7.1 \mathrm{~Hz}, \mathrm{CH}_{3}\right) ; 1.21-$ $1.31\left(\mathrm{~m}, 2 \mathrm{H}, \mathrm{CH}_{2}\right) ; 1.48-1.57\left(\mathrm{~m}, 2 \mathrm{H}, \mathrm{CH}_{2}\right) ; 2.64\left(\mathrm{~d}, 2 \mathrm{H}, J=7.0 \mathrm{~Hz}, \mathrm{CH}_{2}\right) ; 5.69\left(\mathrm{~s}, 2 \mathrm{H}, \mathrm{CH}_{2} \mathrm{~N}\right)$; 7.18-7.28 (m, 2H, Ar); 7.53-7.68 (m, 3H, Ar); 7.84 (d, 1H, J=7.5 Hz, Ar); 8.06 (d, 1H, J=8.0 $\mathrm{Hz}, \mathrm{Ar}) ; 8.67$ (d, 1H, $J=8.4 \mathrm{~Hz}, \mathrm{Ar}) ; 12.13 \mathrm{ppm}$ (br s, 1H). MS m/z: $441\left(\mathrm{M}^{+}, 11\right)$. Anal. Calcd for $\mathrm{C}_{23} \mathrm{H}_{22} \mathrm{ClN}_{3} \mathrm{O}_{5}$ : C 60.60; $\mathrm{H} 4.83 ; \mathrm{N} 9.22$; Found: C 60.28; H 5.15; N 9.53.

3-\{[3-[(4-Chloro-2-butyl-5-carboxy-1H-imidazolyl)methyl]benzoyl]amino\}benzoic acid (6b). (180 mg, 0.39 mmol, yield $52 \%$ ): IR: $1682\left(\mathrm{C}=\mathrm{O}\right.$ of acid), $1643\left(\mathrm{C}=\mathrm{O}\right.$ of amide) $\mathrm{cm}^{-1} .{ }^{1} \mathrm{H}$ NMR (DMSO-d $\left.d_{6}\right) \delta .79\left(\mathrm{t}, 3 \mathrm{H}, J=7.1 \mathrm{~Hz}, \mathrm{CH}_{3}\right) ; 1.20-1.31\left(\mathrm{~m}, 2 \mathrm{H}, \mathrm{CH}_{2}\right) ; 1.46-1.57(\mathrm{~m}, 2 \mathrm{H}$, $\left.\mathrm{CH}_{2}\right) ; 2.62\left(\mathrm{~d}, 2 \mathrm{H}, J=7.1 \mathrm{~Hz}, \mathrm{CH}_{2}\right) ; 5.68\left(\mathrm{~s}, 2 \mathrm{H}, \mathrm{CH}_{2} \mathrm{~N}\right) ; 7.15(\mathrm{~d}, 1 \mathrm{H}, J=7.7 \mathrm{~Hz}, \mathrm{Ar}) ; 7.44-7.58$ (m, 3H, Ar); 7.67-7.70 (m, 2H, Ar); 7.91 (d, 1H, J=7.9 Hz, Ar); 8.02 (d, 1H, J=7.1 Hz, Ar); 8.38 (br s, $1 \mathrm{H}) ; 10.45$ ppm (br s, $1 \mathrm{H}) .{ }^{13} \mathrm{C} \mathrm{NMR}\left(\mathrm{CD}_{3} \mathrm{COCD}_{3}\right): \delta 167.38 ; 166.07 ; 160.74 ; 153.36$; 
$140.34 ; 138.80 ; 137.27 ; 136.50 ; 132.06 ; 130.09 ; 129.73 ; 129.64 ; 127.23 ; 126.76 ; 125.74 ;$ $125.34 ; 122.21 ; 118.15 ; 49.01 ; 30.00 ; 27.31 ; 22.90 ; 13.98 . \mathrm{MS} m / z: 441\left(\mathrm{M}^{+}, 20\right)$. Anal. Calcd for $\mathrm{C}_{23} \mathrm{H}_{22} \mathrm{ClN}_{3} \mathrm{O}_{5}$ : C 60.60; H 4.83; N 9.22; Found: C 60.72; H 4.76; N 8.90.

4-\{[3-[(4-Chloro-2-butyl-5-carboxy-1H-imidazolyl)methyl]benzoyl]amino\}benzoic acid (6c). (190 mg, $0.42 \mathrm{mmol}$, yield $55 \%$ ): ${ }^{1} \mathrm{H}$ NMR (DMSO- $\left.d_{6}\right) \delta 0.80\left(\mathrm{t}, 3 \mathrm{H}, J=7.1 \mathrm{~Hz}, \mathrm{CH}_{3}\right) ; 1.18-$ $1.32\left(\mathrm{~m}, 2 \mathrm{H}, \mathrm{CH}_{2}\right) ; 1.46-1.57\left(\mathrm{~m}, 2 \mathrm{H}, \mathrm{CH}_{2}\right) ; 2.63\left(\mathrm{~d}, 2 \mathrm{H}, J=7.1 \mathrm{~Hz}, \mathrm{CH}_{2}\right) ; 5.68\left(\mathrm{~s}, 2 \mathrm{H}, \mathrm{CH}_{2} \mathrm{~N}\right)$; 7.17 (d, 1H, $J=7.3 \mathrm{~Hz}, \mathrm{Ar}) ; 7.49-7.58$ (m, 1H, Ar); 7.66 (s, 1H, Ar); 7.87-7.96 (m, 4H, Ar); 8.02 (d, $1 \mathrm{H}, J=7.1 \mathrm{~Hz}, \mathrm{Ar}) ; 10.57 \mathrm{ppm}$ (br s, 1H). MS m/z: $441\left(\mathrm{M}^{+}, 9\right)$. Anal. Calcd for $\mathrm{C}_{23} \mathrm{H}_{22} \mathrm{ClN}_{3} \mathrm{O}_{5}$ : C 60.60; H 4.83; N 9.22; Found: C 60.35; H 5.20; N 9.16.

2-[(3-\{[3-(Trifluoromethyl)-1H-pyrazolyl]methyl\}benzoyl)amino]benzoic acid (7a). (180 mg, 0.46 mmol, yield $61 \%$ ): ${ }^{1} \mathrm{H}$ NMR (DMSO- $\left.d_{6}\right) \delta 5.56\left(\mathrm{~s}, 2 \mathrm{H}, \mathrm{CH}_{2} \mathrm{~N}\right) ; 6.78(\mathrm{~d}, 1 \mathrm{H}, J=2.0$ $\mathrm{Hz}$, pyrazole); 7.18-7.25 (m, 1H, Ar); 7.50-7.70 (m, 3H, Ar, pyrazole); 7.88-7.91 (m, 2H, Ar); 8.06 (dd, 1H, $J=1.4,8.1 \mathrm{~Hz}, \mathrm{Ar}) ; 8.16(\mathrm{~d}, 1 \mathrm{H}, J=1.4 \mathrm{~Hz}, \mathrm{Ar}) ; 8.68 \mathrm{ppm}(\mathrm{d}, 1 \mathrm{H}, J=7.5 \mathrm{~Hz}, \mathrm{Ar})$. MS m/z: $389\left(\mathrm{M}^{+}, 15\right) ; 137\left(\mathrm{M}^{+}-\mathrm{HNPhCOOH}, 100\right)$. Anal. Calcd for $\mathrm{C}_{19} \mathrm{H}_{14} \mathrm{~F}_{3} \mathrm{~N}_{3} \mathrm{O}_{3}: \mathrm{C} 58.61 ; \mathrm{H}$ 3.50; N 10.79; Found: C 58.42; H 3.65; N 10.73.

3-[(3-\{[3-(Trifluoromethyl)-1H-pyrazolyl]methyl\}benzoyl)amino]benzoic acid (7b). (130 mg, 0.33 mmol, yield $44 \%$ ): IR: 1689 (C=O of acid), $1645\left(\mathrm{C}=\mathrm{O}\right.$ of amide) $\mathrm{cm}^{-1} .{ }^{1} \mathrm{H}$ NMR $\left(\mathrm{DMSO}-d_{6}\right) \delta 5.54\left(\mathrm{~s}, 2 \mathrm{H}, \mathrm{CH}_{2} \mathrm{~N}\right) ; 6.76-6.80(\mathrm{~m}, 1 \mathrm{H}$, pyrazole); 7.44-7.58 (m, 3H, Ar, pyrazole); 7.51 (d, 1H, $J=7.7 \mathrm{~Hz}, \mathrm{Ar})$; 7.91-8.05 (m, 3H, Ar); 8.15 (s, 1H, Ar); 8.39 ppm (s, 1H, Ar). MS $m / z: 389\left(\mathrm{M}^{+}, 12\right) ; 137\left(\mathrm{M}^{+}-\mathrm{HNPhCOOH}, 100\right) .{ }^{13} \mathrm{C} \mathrm{NMR}\left(\mathrm{CD}_{3} \mathrm{COCD}_{3}\right): \delta 167.40 ; 166.11$; $144.44 ; 140.45 ; 137.87 ; 137.27 ; 136.65 ; 132.82 ; 131.99 ; 131.10 ; 129.78 ; 129.67 ; 128.31$; $128.00 ; 125.78 ; 125.38 ; 122.28 ; 105.35 ; 56.71$. MS $m / z: 389\left(\mathrm{M}^{+}, 17\right)$. Anal. Calcd for $\mathrm{C}_{19} \mathrm{H}_{14} \mathrm{~F}_{3} \mathrm{~N}_{3} \mathrm{O}_{3}$ : C 58.61; H 3.50; N 10.79; Found: C 58.75; H 3.28; N 10.89.

4-[(3-\{[3-(Trifluoromethyl)-1H-pyrazolyl]methyl\}benzoyl)amino]benzoic acid (7c). (124 mg, $0.32 \mathrm{mmol}$, yield $42 \%):{ }^{1} \mathrm{H}$ NMR (DMSO- $\left.d_{6}\right) \delta 5.54\left(\mathrm{~s}, 2 \mathrm{H}, \mathrm{CH}_{2} \mathrm{~N}\right) ; 6.77-6.80(\mathrm{~m}, 1 \mathrm{H}$, pyrazole); 7.46-7.60 (m, 2H, Ar); 7.86-7.93 (m, 6H, Ar); 8.14-8.16 ppm (m, 1H, pyrazole). MS $m / z: 389\left(\mathrm{M}^{+}, 58\right)$. Anal. Calcd for $\mathrm{C}_{19} \mathrm{H}_{14} \mathrm{~F}_{3} \mathrm{~N}_{3} \mathrm{O}_{3}$ : C 58.61; H 3.50; N 10.79; Found: C 58.34; $\mathrm{H}$ $3.15 ; \mathrm{N} 10.94$.

\section{General procedure for the preparation of compounds 9a-c}

Thionyl chloride $(1.60 \mathrm{~mL}, 22.00 \mathrm{mmol})$ was added dropwise to a solution of the opportune aminobenzoic acid 8a-c $(2.00 \mathrm{~g} ; 15.00 \mathrm{mmol})$ in $\mathrm{EtOH}$ absolute $(23 \mathrm{~mL})$, cooled at $0{ }^{\circ} \mathrm{C}$. The resulting mixture was refluxed for $48 \mathrm{~h}$, then the solvent was evaporated and the aqueous phase was extracted with AcOEt. The organic phase was washed with aqueous $\mathrm{KOH}$, dried over $\mathrm{NaSO}_{4}$ and the solvent evaporated to give 9a-c.

Ethyl 2-aminobenzoate (9a). (1.61 g, $9.75 \mathrm{mmol}$, yield $65 \%$ ) from 8a: ${ }^{1} \mathrm{H} \mathrm{NMR}\left(\mathrm{CDCl}_{3}\right) \delta 1.38$ (t, 3H, J=7.1 Hz, $\mathrm{CH}_{3}$ ); 4.33 (q, 2H, J=7.1 Hz, $\mathrm{CH}_{2}$ ); 6.07-6.69 (m, 2H, Ar); 7.22-7.31 (m, 1H, Ar); $7.87 \mathrm{ppm}\left(\mathrm{d}, 1 \mathrm{H}, J=8.4 \mathrm{~Hz}\right.$, Ar). Anal. Calcd for $\mathrm{C}_{9} \mathrm{H}_{11} \mathrm{NO}_{2}$ : C 65.45; $\mathrm{H} 6.71 ; \mathrm{N} 8.48$; Found: C 65.06; H 6.53; N 7.92. 
Ethyl 3-aminobenzoate (9b). (2.23 g, $13.50 \mathrm{mmol}$, yield $90 \%)$ from $8 \mathbf{b}:{ }^{1} \mathrm{H} \mathrm{NMR}\left(\mathrm{CDCl}_{3}\right) \delta$ $1.36\left(\mathrm{t}, 3 \mathrm{H}, J=7.1 \mathrm{~Hz}, \mathrm{CH}_{3}\right) ; 4.33$ (q, 2H, $\left.J=7.1 \mathrm{~Hz}, \mathrm{CH}_{2}\right) ; 6.81-6.87$ (m, 1H, Ar); 7.19 (t, 1H, $J=7.8 \mathrm{~Hz}, \mathrm{Ar}) ; 7.35$ (s, 1H, Ar); $7.39 \mathrm{ppm}(\mathrm{d}, 1 \mathrm{H}, J=7.7 \mathrm{~Hz}, \mathrm{Ar})$. Anal. Calcd for $\mathrm{C}_{9} \mathrm{H}_{11} \mathrm{NO}_{2}: \mathrm{C}$ 65.45; H 6.71; N 8.48; Found: C 65.23; H 6.60; N 8.02.

Ethyl 4-aminobenzoate (9c). (1.04 g, $6.30 \mathrm{mmol}$, yield $42 \%)$ from 8c: ${ }^{1} \mathrm{H}$ NMR (DMSO- $\left.d_{6}\right) \delta$ $1.28\left(\mathrm{t}, 3 \mathrm{H}, J=7.1 \mathrm{~Hz}, \mathrm{CH}_{3}\right) ; 4.23$ (q, 2H, $\left.J=7.1 \mathrm{~Hz}, \mathrm{CH}_{2}\right) ; 6.87$ (d, 2H, $\left.J=8.6 \mathrm{~Hz}, \mathrm{AA}^{\prime} \mathrm{XX}^{\prime}\right)$; 7.77 ppm (d, $\left.2 \mathrm{H}, J=8.6 \mathrm{~Hz}, \mathrm{AA}^{\prime} \mathrm{XX}^{\prime}\right)$. Anal. Calcd for $\mathrm{C}_{9} \mathrm{H}_{11} \mathrm{NO}_{2}$ : C 65.45; $\mathrm{H}$ 6.71; N 8.48; Found: C 65.31; H 6.48; N 8.25.

\section{General procedure for the preparation of compounds 12a-c and 13a-c}

A solution of the opportune amine 9a-c $(0.45 \mathrm{~g} ; 2.51 \mathrm{mmol})$ and triethylamine $(1 \mathrm{~mL})$ in $\mathrm{CH}_{2} \mathrm{Cl}_{2}$ $(5 \mathrm{~mL})$ was added dropwise to a solution of 4-(chloromethyl)benzoyl chloride 10 (or of 3(chloromethyl)benzoylchloride 11) $(0.47 \mathrm{~g} ; 2.51 \mathrm{mmol})$ in $\mathrm{CH}_{2} \mathrm{Cl}_{2}(3 \mathrm{ml})$. The reaction mixture was stirred at room temperature for $20 \mathrm{~h}$, and then washed with $1 \mathrm{~N} \mathrm{HCl}$ and $1 \mathrm{~N} \mathrm{NaOH}$. The solvent was dried and evaporated to give the amide 12a-c, 13a-c.

Ethyl-2-[(4-chloromethyl-benzoyl)amino]-benzoate (12a). (438 mg, $1.38 \mathrm{mmol}, 55 \%$ from 9a and 10: ${ }^{1} \mathrm{H}$ NMR $\left(\mathrm{CDCl}_{3}\right) \delta 1.44\left(\mathrm{t}, 3 \mathrm{H}, J=7.1 \mathrm{~Hz}, \mathrm{CH}_{3}\right) ; 4.43\left(\mathrm{q}, 2 \mathrm{H}, J=7.1 \mathrm{~Hz}, \mathrm{CH}_{2}\right) ; 4.65$ (s, 2H, $\mathrm{CH}_{2} \mathrm{Cl}$ ); 7.14 (t, $\left.1 \mathrm{H}, J=7.7 \mathrm{~Hz}, \mathrm{Ar}\right) ; 7.53-7.65$ (m, 3H, Ar); 8.03-8.17 (m, 3H, Ar); 8.92 (d, $1 \mathrm{H}, J=8.4$, Ar); 12.13 ppm (br s, $1 \mathrm{H}, \mathrm{NH}$ ). Anal. Calcd for $\mathrm{C}_{17} \mathrm{H}_{16} \mathrm{ClNO}_{3}$ : C 64.26; H 5.04; N 4.40; Found: C 64.19; H 4.80; N 4.32.

Ethyl-3-[(4-chloromethyl-benzoyl)amino]-benzoate (12b). (295 mg, $0.93 \mathrm{mmol}, 37$ \%) from 9b and 10: ${ }^{1} \mathrm{H}$ NMR $\left(\mathrm{CDCl}_{3}\right) \delta 1.39\left(\mathrm{t}, 3 \mathrm{H}, J=7.1 \mathrm{~Hz}, \mathrm{CH}_{3}\right) ; 4.36\left(\mathrm{q}, 2 \mathrm{H}, J=7.1 \mathrm{~Hz}, \mathrm{CH}_{2}\right) ; 4.64$ $\left(\mathrm{s}, 2 \mathrm{H}, \mathrm{CH}_{2} \mathrm{Cl}\right) ; 7.42-7.50$ (m, 1H, Ar); 7.52 (d, 2H, $\left.J=8.1 \mathrm{~Hz}, \mathrm{AA}^{\prime} X X^{\prime}\right)$; 7.82-7.87 (m, 1H, Ar); $7.88\left(\mathrm{~d}, 2 \mathrm{H}, J=8.1 \mathrm{~Hz}, \mathrm{AA}^{\prime} \mathrm{XX}^{\prime}\right) ; 8.00-8.11 \mathrm{ppm}(\mathrm{m}, 2 \mathrm{H}$, Ar). Anal. Calcd for $\mathrm{C}_{17} \mathrm{H}_{16} \mathrm{ClNO}_{3}$ : C 64.26; H 5.04; N 4.40; Found: C 63.89; H 5.40; N 4.09.

Ethyl-4-[(4-chloromethyl-benzoyl)amino]-benzoate (12c). (318 mg, $1.00 \mathrm{mmol}, 40 \%)$ from 9c and 10: ${ }^{1} \mathrm{H}$ NMR $\left(\mathrm{CDCl}_{3}\right) \delta 1.40\left(\mathrm{t}, 3 \mathrm{H}, J=7.1 \mathrm{~Hz}, \mathrm{CH}_{3}\right) ; 4.37\left(\mathrm{q}, 2 \mathrm{H}, J=7.1 \mathrm{~Hz}, \mathrm{CH}_{2}\right) ; 4.64$ (s, 2H, $\mathrm{CH}_{2} \mathrm{Cl}$ ); 7.52 (d, 2H, $\left.J=8.2 \mathrm{~Hz}, \mathrm{AA}^{\prime} \mathrm{XX}^{\prime}\right) ; 7.74$ (d, 2H, J=8.7 Hz, AA'XX'); 7.87 (d, $\left.2 \mathrm{H}, J=8.2 \mathrm{~Hz}, \mathrm{AA}^{\prime} \mathrm{XX} \mathrm{X}^{\prime}\right) ; 8.07 \mathrm{ppm}\left(\mathrm{d}, 2 \mathrm{H}, J=8.7 \mathrm{~Hz}, \mathrm{AA}^{\prime} \mathrm{XX} \mathrm{X}^{\prime}\right)$. Anal. Calcd for $\mathrm{C}_{17} \mathrm{H}_{16} \mathrm{ClNO}_{3}$ : C 64.26; H 5.04; N 4.40; Found: C 64.07; H 5.21; N 4.46.

Ethyl-2-[(3-chloromethyl-benzoyl)amino]benzoate (13a). (183 mg, $0.58 \mathrm{mmol}, 23 \%$ ) from 9a and 11: ${ }^{1} \mathrm{H} \mathrm{NMR}\left(\mathrm{CDCl}_{3}\right) \delta 1.44\left(\mathrm{t}, 3 \mathrm{H}, J=7.1 \mathrm{~Hz}, \mathrm{CH}_{3}\right) ; 4.43\left(\mathrm{q}, 2 \mathrm{H}, J=7.1 \mathrm{~Hz}, \mathrm{CH}_{2}\right) ; 4.68(\mathrm{~s}$, $2 \mathrm{H}, \mathrm{CH}_{2} \mathrm{Cl}$ ); 7.14 (dt, 2H, $\left.J=1.2,8.5 \mathrm{~Hz}, \mathrm{Ar}\right) ; 7.49-7.65$ (m, 3H, Ar); 7.98 (m, 1H, Ar); 8.08$8.13(\mathrm{~m}, 2 \mathrm{H}, \mathrm{Ar}) ; 8.91$ (dd, $1 \mathrm{H}, J=1.0,8.5 \mathrm{~Hz}, \mathrm{Ar}) ; 12.12 \mathrm{ppm}$ (br s, $1 \mathrm{H})$. Anal. Calcd for $\mathrm{C}_{17} \mathrm{H}_{16} \mathrm{ClNO}_{3}$ : C 64.26; H 5.04; N 4.40; Found: C 64.10; H 5.32; N 4.57.

Ethyl-3-[(3-chloromethyl-benzoyl)amino]benzoate (13b). (318 mg, $1.00 \mathrm{mmol}, 40$ \%) from 9b and 11: ${ }^{1} \mathrm{H} \mathrm{NMR}\left(\mathrm{CDCl}_{3}\right) \delta 1.36\left(\mathrm{t}, 3 \mathrm{H}, J=7.1 \mathrm{~Hz}, \mathrm{CH}_{3}\right) ; 4.33\left(\mathrm{q}, 2 \mathrm{H}, J=7.1 \mathrm{~Hz}, \mathrm{CH}_{2}\right) ; 4.60(\mathrm{~s}$, $2 \mathrm{H}, \mathrm{CH}_{2} \mathrm{Cl}$ ); 7.38-7.47 (m, 2H, Ar); 7.53-7.57 (m, 1H, Ar); 7.79-7.84 (m, 2H, Ar); 7.90 (s, 1H, Ar); 8.04-8.09 (m, 1H, Ar); $8.16(\mathrm{~s}, 1 \mathrm{H}, \mathrm{Ar}) ; 8.38 \mathrm{ppm}$ (br s, 1H, NH). Anal. Calcd for $\mathrm{C}_{17} \mathrm{H}_{16} \mathrm{ClNO}_{3}$ : C 64.26; H 5.04; N 4.40; Found: C 64.33; H 5.25; N 4.73. 
Ethyl-4-[(3-chloromethyl-benzoyl)amino]benzoate (13c). (358 mg, $1.13 \mathrm{mmol}, 45 \%$ ) from 9c and 11: ${ }^{1} \mathrm{H}$ NMR $\left(\mathrm{CDCl}_{3}\right) \delta 1.40\left(\mathrm{t}, 3 \mathrm{H}, J=7.1 \mathrm{~Hz}, \mathrm{CH}_{3}\right) ; 4.37\left(\mathrm{q}, 2 \mathrm{H}, J=7.1 \mathrm{~Hz}, \mathrm{CH}_{2}\right) ; 4.65(\mathrm{~s}$, $2 \mathrm{H}, \mathrm{CH}_{2} \mathrm{Cl}$ ); 7.46-7.62 (m, 2H, Ar); 7.75 (d, 2H, $J=8.6 \mathrm{~Hz}, \mathrm{AA}^{\prime} \mathrm{XX}^{\prime}$ ); 7.81-7.85 (m, 1H, Ar); 7.91 (s, $1 \mathrm{H}, \mathrm{Ar}) ; 8.07 \mathrm{ppm}\left(\mathrm{d}, 2 \mathrm{H}, J=8.6 \mathrm{~Hz}\right.$, AA'XX'). Anal. Calcd for $\mathrm{C}_{17} \mathrm{H}_{16} \mathrm{ClNO}_{3}$ : $\mathrm{C}_{64.26}$; H 5.04; N 4.40; Found: C 64.01; H 5.39; N 4.45 .

\section{General procedure for the preparation of compounds $15 \mathrm{a}-\mathrm{c}, 16 \mathrm{a}-\mathrm{c}$}

To a solution of the opportune arilmethylchloride 12a-c, 13a-c $(0.25 \mathrm{~g}, 0.75 \mathrm{mmol})$ in DMAC (2.1 mL) was added 2-butyl-4-chloro-5-formil-imidazole $14(0.14 \mathrm{~g} ; 0.76 \mathrm{mmol})$ dissolved in DMAC $(0.85 \mathrm{ml})$. The resulting solution was cooled to $-10^{\circ} \mathrm{C}$ and $\mathrm{K}_{2} \mathrm{CO}_{3}(99 \mathrm{mg} ; 0.72 \mathrm{mmol})$ was added. The mixture was stirred at room temperature for $12 \mathrm{~h}$, then the suspension was filtered and the solvent evaporated to give compounds 15a-c, 16a-c.

Ethyl-2-\{[4-((2-butyl-4-chloro-5-formyl-1H-imidazolyl)methyl)benzoyl]amino\}benzoate (15a). Purified by column chromatography eluting with AcOEt $/ n$-hexane (8:2) afforded 15a (89 mg, 0.19 mmol, yield $25 \%$ ) from 12a: ${ }^{1} \mathrm{H}$ NMR $\left(\mathrm{CDCl}_{3}\right) \delta 0.88\left(\mathrm{t}, 3 \mathrm{H}, J=7.2 \mathrm{~Hz}, \mathrm{CH}_{3}\right) ; 1.25-$ $1.37\left(\mathrm{~m}, 2 \mathrm{H}, \mathrm{CH}_{2}\right) ; 1.42\left(\mathrm{t}, 3 \mathrm{H}, J=7.1 \mathrm{~Hz}, \mathrm{CH}_{3}\right) ; 1.61-1.75\left(\mathrm{~m}, 2 \mathrm{H}, \mathrm{CH}_{2}\right) ; 2.58-2.66(\mathrm{~m}, 2 \mathrm{H}$, $\left.\mathrm{CH}_{2}\right) ; 4.40\left(\mathrm{q}, 2 \mathrm{H}, J=7.1 \mathrm{~Hz}, \mathrm{CH}_{2}\right) ; 5.63\left(\mathrm{~s}, 2 \mathrm{H}, \mathrm{CH}_{2} \mathrm{~N}\right) ; 7.09-7.20(\mathrm{~m}, 3 \mathrm{H}, \mathrm{Ar}) ; 7.56-7.64$ (m, $1 \mathrm{H}, \mathrm{Ar}) ; 8.02$ (d, 2H, $J=8.1 \mathrm{~Hz}, \mathrm{Ar}) ; 8.08-8.12$ (m, 1H, Ar); 8.90 (d, 1H, J=8.6 Hz, Ar); 9.76 (s, 1H, CHO); 12.12 ppm (br s, $1 \mathrm{H}, \mathrm{NH}$ ). MS m/z: $389\left(\mathrm{M}^{+}, 17\right)$. Anal. Calcd for $\mathrm{C}_{25} \mathrm{H}_{26} \mathrm{ClN}_{3} \mathrm{O}_{4}$ : C 64.17; H 5.56; N 8.98; Found: C 64.05; H 5.71; N 8.83.

Ethyl-3-\{[4-((2-butyl-4-chloro-5-formyl-1H-imidazolyl)methyl)benzoyl]amino\}benzoate (15b). (316 mg, $0.67 \mathrm{mmol}$, yield $90 \%$ ) from 12b: ${ }^{1} \mathrm{H} \mathrm{NMR}\left(\mathrm{CDCl}_{3}\right) \delta 0.87(\mathrm{t}, 3 \mathrm{H}, J=7.3 \mathrm{~Hz}$, $\left.\mathrm{CH}_{3}\right)$; 1.24-1.37 (t, 3H, J=7.1 Hz, $\left.\mathrm{CH}_{3}\right) ; 1.41\left(\mathrm{~m}, 2 \mathrm{H}, \mathrm{CH}_{2}\right) ; 1.60-1.75\left(\mathrm{~m}, 2 \mathrm{H}, \mathrm{CH}_{2}\right) ; 2.60(\mathrm{t}$, $\left.2 \mathrm{H}, J=7.6 \mathrm{~Hz}, \mathrm{CH}_{2}\right) ; 4.35\left(\mathrm{q}, 2 \mathrm{H}, J=7.1 \mathrm{~Hz}, \mathrm{CH}_{2}\right) ; 5.58\left(\mathrm{~s}, 2 \mathrm{H}, \mathrm{CH}_{2} \mathrm{~N}\right) ; 7.10(\mathrm{~d}, 2 \mathrm{H}, J=7.8$ $\mathrm{Hz}, \mathrm{Ar}) ; 7.42$ (t, 1H, $J=7.9 \mathrm{~Hz}, \mathrm{Ar}) ; 7.78-7.87$ (m, 3H, Ar); 8.05 (d, 1H, J=8.1 Hz, Ar); 8.13 $(\mathrm{d}, 1 \mathrm{H}, J=1.3 \mathrm{~Hz}, \mathrm{Ar}) ; 8.42(\mathrm{~s}, 1 \mathrm{H}, \mathrm{CHO}) ; 9.73 \mathrm{ppm}(\mathrm{br} \mathrm{s}, 1 \mathrm{H}, \mathrm{NH})$. Anal. Calcd for $\mathrm{C}_{25} \mathrm{H}_{26} \mathrm{ClN}_{3} \mathrm{O}_{4}$ : C 64.17; H 5.56; N 8.98; Found: C 63.77; H 5.96; N 8.50.

Ethyl-4-\{[4-((2-butyl-4-chloro-5-formyl-1 $\boldsymbol{H}$-imidazolyl)methyl)benzoyl]amino\}benzoate (15c). (316 mg, $0.67 \mathrm{mmol}$, yield $90 \%$ ) from 12c: ${ }^{1} \mathrm{H} \mathrm{NMR}\left(\mathrm{CDCl}_{3}\right) \delta 0.88(\mathrm{t}, 3 \mathrm{H}, J=7.2 \mathrm{~Hz}$, $\left.\mathrm{CH}_{3}\right)$; 1.24-1.39 (t, 3H, J=7.1 Hz, $\left.\mathrm{CH}_{3}\right) ; 1.42\left(\mathrm{~m}, 2 \mathrm{H}, \mathrm{CH}_{2}\right) ; 1.61-1.79$ (m, 2H, $\left.\mathrm{CH}_{2}\right) ; 2.56-2.65$ $\left(\mathrm{m}, 2 \mathrm{H}, \mathrm{CH}_{2}\right) ; 4.35\left(\mathrm{q}, 2 \mathrm{H}, J=7.1 \mathrm{~Hz}, \mathrm{CH}_{2} \mathrm{~N}\right) ; 5.59\left(\mathrm{~s}, 2 \mathrm{H}, \mathrm{CH}_{2}\right) ; 7.12(\mathrm{~d}, 2 \mathrm{H}, J=8.1 \mathrm{~Hz}$, AA'XX'); 7.50 (d, 2H, $\left.J=7.8 \mathrm{~Hz}, \mathrm{AA}^{\prime} \mathrm{XX}^{\prime}\right) ; 7.84$ (d, 2H, $\left.J=7.8 \mathrm{~Hz}, \mathrm{AA}^{\prime} \mathrm{XX}^{\prime}\right) ; 8.04$ (d, 2H, $J$ $\left.=8.1 \mathrm{~Hz}, \mathrm{AA}^{\prime} \mathrm{XX} \mathrm{X}^{\prime}\right) ; 9.73 \mathrm{ppm}(\mathrm{s}, 1 \mathrm{H}, \mathrm{CHO})$. Anal. Calcd for $\mathrm{C}_{25} \mathrm{H}_{26} \mathrm{ClN}_{3} \mathrm{O}_{4}$ : C 64.17; $\mathrm{H}$ 5.56; $\mathrm{N}$ 8.98; Found: C 63.97; H 5.45; N 8.95.

\section{Ethyl-2-\{[3-((2-butyl-4-chloro-5-formyl-1H-imidazolyl)methyl)benzoyl]amino\}benzoate}

(16a). Purified by crystallization from EtOH afforded 16a (196 mg, $0.42 \mathrm{mmol}$, yield $56 \%$ ) from 13a: ${ }^{1} \mathrm{H}$ NMR $\left(\mathrm{CDCl}_{3}\right) \delta 0.86\left(\mathrm{t}, 3 \mathrm{H}, J=7.3 \mathrm{~Hz}, \mathrm{CH}_{3}\right) ; 1.25-1.48\left(\mathrm{~m}, 2 \mathrm{H}, \mathrm{CH}_{2}\right) ; 1.44(\mathrm{t}$, $\left.3 \mathrm{H}, J=7.1 \mathrm{~Hz}, \mathrm{CH}_{3}\right) ; 1.58-1.76\left(\mathrm{~m}, 2 \mathrm{H}, \mathrm{CH}_{2}\right) ; 2.66\left(\mathrm{t}, 2 \mathrm{H}, J=7.3 \mathrm{~Hz}, \mathrm{CH}_{2}\right) ; 4.44(\mathrm{q}, 2 \mathrm{H}, J=7.1$ $\left.\mathrm{Hz}, \mathrm{CH}_{2}\right) ; 5.65\left(\mathrm{~s}, 2 \mathrm{H}, \mathrm{CH}_{2} \mathrm{~N}\right) ; 7.33(\mathrm{t}, 1 \mathrm{H}, J=7.9 \mathrm{~Hz}, \mathrm{Ar}) ; 7.26-7.30$ (m, 1H, Ar); 7.47- 7.64 (m, 2H, Ar); 7.72 (s, 1H, Ar); 7.98 (d, 1H, J=7.9 Hz); 8.10 (dd, 1H, J=1.6, 8.1 Hz, Ar); 8.89 (d, 
$1 \mathrm{H}, J=8.4 \mathrm{~Hz}, \mathrm{Ar}) ; 9.79(\mathrm{~s}, 1 \mathrm{H}, \mathrm{CHO}) ; 12.11 \mathrm{ppm}$ (br s, 1H, NH). Anal. Calcd for $\mathrm{C}_{25} \mathrm{H}_{26} \mathrm{ClN}_{3} \mathrm{O}_{4}$ : C 64.17; H 5.56; N 8.98; Found: C 64.31; H 5.68; N 8.75.

Ethyl-3-\{[3-((2-butyl-4-chloro-5-formyl-1H-imidazolyl)methyl)benzoyl]amino\}benzoate (16b). (284 mg, $0.61 \mathrm{mmol}$, yield $80 \%$ ) from 13b: ${ }^{1} \mathrm{H} \mathrm{NMR}\left(\mathrm{CDCl}_{3}\right) \delta 0.86(\mathrm{t}, 3 \mathrm{H}, J=7.1 \mathrm{~Hz}$, $\left.\mathrm{CH}_{3}\right)$; 1.23-1.41 (m, 2H, CH$) ; 1.37\left(\mathrm{t}, 3 \mathrm{H}, J=7.1 \mathrm{~Hz}, \mathrm{CH}_{3}\right) ; 1.55-1.71\left(\mathrm{~m}, 2 \mathrm{H}, \mathrm{CH}_{2}\right) ; 2.62(\mathrm{t}$, $\left.2 \mathrm{H}, J=7.3 \mathrm{~Hz}, \mathrm{CH}_{2}\right) ; 4.35\left(\mathrm{q}, 2 \mathrm{H}, J=7.1 \mathrm{~Hz}, \mathrm{CH}_{2}\right) ; 5.57\left(\mathrm{~s}, 2 \mathrm{H}, \mathrm{CH}_{2} \mathrm{~N}\right) ; 7.12(\mathrm{~d}, 1 \mathrm{H}, J=7.7$ $\mathrm{Hz}, \mathrm{Ar}$ ); 7.37-7.46 (m, 3H, Ar); 7.73- 7.82 (m, 2H, Ar); 8.05 (d, 1H, J=8.1 Hz, Ar); 8.15 (s, 1H, Ar); 8.77 (br s, $1 \mathrm{H}, \mathrm{NH}$ ); 9.20 ppm (s, $1 \mathrm{H}, \mathrm{CHO}$ ). Anal. Calcd for $\mathrm{C}_{25} \mathrm{H}_{26} \mathrm{ClN}_{3} \mathrm{O}_{4}: \mathrm{C} 64.17 ; \mathrm{H}$ 5.56; N 8.98; Found: C 64.09; H 5.34; N 8.85.

\section{Ethyl-4-\{[3-((2-butyl-4-chloro-5-formyl-1H-imidazolyl)methyl)benzoyl]amino\}benzoate}

(16c). (316 mg, $0.67 \mathrm{mmol}$, yield $90 \%$ ) from 13c: ${ }^{1} \mathrm{H} \mathrm{NMR}\left(\mathrm{CDCl}_{3}\right) \delta 0.88(\mathrm{t}, 3 \mathrm{H}, J=7.1 \mathrm{~Hz}$, $\left.\mathrm{CH}_{3}\right) ; 1.33-1.43\left(\mathrm{~m}, 2 \mathrm{H}, \mathrm{CH}_{2}\right) ; 1.39$ (t, 3H, J=7.1 Hz, $\left.\mathrm{CH}_{3}\right) ; 1.65-1.74\left(\mathrm{~m}, 2 \mathrm{H}, \mathrm{CH}_{2}\right) ; 2.58-3.68$ $\left(\mathrm{m}, 2 \mathrm{H}, \mathrm{CH}_{2}\right) ; 4.37$ (q, 2H, $\left.J=7.1 \mathrm{~Hz}, \mathrm{CH}_{2}\right) ; 5.60\left(\mathrm{~s}, 2 \mathrm{H}, \mathrm{CH}_{2} \mathrm{~N}\right) ; 7.12(\mathrm{~d}, 1 \mathrm{H}, J=8.1 \mathrm{~Hz}, \mathrm{Ar})$; 7.40-7.52 (m, 2H, Ar); 7.74 (d, 2H, $\left.J=8.7 \mathrm{~Hz}, \mathrm{AA}^{\prime} \mathrm{XX}^{\prime}\right)$; 8.05 (d, 2H, $J=8.7 \mathrm{~Hz}, \mathrm{AA}^{\prime} \mathrm{XX}^{\prime}$ ); 8.37 (s, $1 \mathrm{H}, \mathrm{Ar}) ; 9.74$ ppm (s, 1H, CHO). Anal. Calcd for $\mathrm{C}_{25} \mathrm{H}_{26} \mathrm{ClN}_{3} \mathrm{O}_{4}: \mathrm{C}$ 64.17; $\mathrm{H} 5.56 ; \mathrm{N}$ 8.98; Found: C 64.23; H 5.31; N 8.79.

\section{General procedure for the preparation of compounds 19a-c, 20a-c}

A solution of $\mathrm{NaClO}_{2}(531 \mathrm{mg}, 5.87 \mathrm{mmol})$ and $\mathrm{NaH}_{2} \mathrm{PO}_{4}(534 \mathrm{mg}, 4.45 \mathrm{mmol})$ in $\mathrm{H}_{2} \mathrm{O}(5.0 \mathrm{~mL})$ was added dropwise to a solution of compound 15a-c, 16a-c (300 mg, $0.64 \mathrm{mmol})$ in $\mathrm{t}-\mathrm{BuOH}$ $(5.0 \mathrm{~mL})$. The mixture was stirred for $7 \mathrm{~h}$ at room temperature, then AcOEt was added and the organic phase was separated and washed with $\mathrm{H}_{2} \mathrm{O}$ and $\mathrm{NaCl}$. The organic phase was evaporated obtained a residue that was dissolved in AcOEt and extracted with $\mathrm{NaHCO}_{3}$. The aqueous layer was acidified to $\mathrm{pH}=3$ with $1 \mathrm{~N} \mathrm{HCl}$ and extracted with AcOEt. The organic phase was dried over $\mathrm{NaSO}_{4}$ and the solvent was evaporated to yield 19a-c, 20a-c.

Ethyl-2-\{[4-((2-butyl-4-chloro-5-carboxy-1H-imidazolyl)methyl)benzoyl]amino\}benzoate (19a). Purified by trituration with $\mathrm{n}$-hexane afforded 19a (161 $\mathrm{mg}, 0.33 \mathrm{mmol}, 52 \%$ yield) from 15a: $\mathrm{mp} 128-130{ }^{\circ} \mathrm{C} ;{ }^{1} \mathrm{H} \mathrm{NMR}\left(\mathrm{CDCl}_{3}\right) \delta 0.87\left(\mathrm{t}, 3 \mathrm{H}, J=7.1 \mathrm{~Hz}, \mathrm{CH}_{3}\right) ; 1.28-1.45\left(\mathrm{~m}, 2 \mathrm{H}, \mathrm{CH}_{2}\right)$; $1.42\left(\mathrm{t}, 3 \mathrm{H}, J=7.1 \mathrm{~Hz}, \mathrm{CH}_{3}\right) ; 1.60-1.72\left(\mathrm{~m}, 2 \mathrm{H}, \mathrm{CH}_{2}\right) ; 2.62\left(\mathrm{t}, 2 \mathrm{H}, J=7.5 \mathrm{~Hz}, \mathrm{CH}_{2}\right) ; 4.42(\mathrm{q}, 2 \mathrm{H}$, $\left.J=7.1 \mathrm{~Hz}, \mathrm{CH}_{2}\right) ; 5.62\left(\mathrm{~s}, 2 \mathrm{H}, \mathrm{CH}_{2} \mathrm{~N}\right) ; 7.09-7.16(\mathrm{~m}, 3 \mathrm{H}, \mathrm{Ar}) ; 7.59$ (t, $\left.1 \mathrm{H}, J=7.1 \mathrm{~Hz}, \mathrm{Ar}\right)$; 7.99$8.11(\mathrm{~m}, 3 \mathrm{H}, \mathrm{Ar}) ; 8.89(\mathrm{~d}, 1 \mathrm{H}, J=8.4 \mathrm{~Hz}, \mathrm{Ar}) ; 12.11 \mathrm{ppm}$ (br s, 1H, NH). Anal. Calcd for $\mathrm{C}_{25} \mathrm{H}_{26} \mathrm{ClN}_{3} \mathrm{O}_{5}$ : C 62.05; H 5.38; N 8.69; Found: C 61.96; H 5.56; N 8.39.

Ethyl-3-\{[4-((2-butyl-4-chloro-5-carboxy-1H-imidazolyl)methyl)benzoyl]amino $\}$ benzoate (19b). (263 mg, $0.54 \mathrm{mmol}, 85 \%$ yield) from 15b: mp $72-74{ }^{\circ} \mathrm{C} ;{ }^{1} \mathrm{H}$ NMR (DMSO- $\left.d_{6}\right) \delta 0.81(\mathrm{t}$, $\left.3 \mathrm{H}, J=7.3 \mathrm{~Hz}, \mathrm{CH}_{3}\right) ; 1.23-1.36\left(\mathrm{~m}, 2 \mathrm{H}, \mathrm{CH}_{2}\right) ; 1.33\left(\mathrm{t}, 3 \mathrm{H}, J=7.1 \mathrm{~Hz}, \mathrm{CH}_{3}\right) ; 1.47-1.59(\mathrm{~m}, 2 \mathrm{H}$, $\mathrm{CH}_{2}$ ); 2.62 (t, 2H, $\left.J=7.1 \mathrm{~Hz}, \mathrm{CH}_{2}\right) ; 4.33$ (q, 2H, $\left.J=7.1 \mathrm{~Hz}, \mathrm{CH}_{2}\right) ; 5.67\left(\mathrm{~s}, 2 \mathrm{H}, \mathrm{CH}_{2} \mathrm{~N}\right) ; 7.14$ (d, $\left.2 \mathrm{H}, J=8.3 \mathrm{~Hz}, \mathrm{AA}^{\prime} \mathrm{XX}^{\prime}\right) ; 7.50$ (t, $\left.1 \mathrm{H}, J=8.0 \mathrm{~Hz}, \mathrm{Ar}\right) ; 7.69$ (d, 1H, $\left.J=8.0 \mathrm{~Hz}, \mathrm{Ar}\right) ; 7.93$ (d, 2H, $J=8.3 \mathrm{~Hz}, \mathrm{AA}^{\prime} \mathrm{XX}^{\prime}$ ); 8.04-8.08 (m, 1H, Ar); 8.40-8.42 (m, 1H, Ar); 10.45 ppm (br s, 1H, NH). Anal. Calcd for $\mathrm{C}_{25} \mathrm{H}_{26} \mathrm{ClN}_{3} \mathrm{O}_{5}$ : C 62.05; H 5.38; N 8.69; Found: C 62.10; H 5.02; N 8.41. 
Ethyl-4-\{[4-((2-butyl-4-chloro-5-carboxy-1H-imidazolyl)methyl)benzoyl]amino\}benzoate (19c). (139 mg, $0.29 \mathrm{mmol}, 45 \%$ yield) from 15c: $\mathrm{mp} 155-158{ }^{\circ} \mathrm{C} ;{ }^{1} \mathrm{H} \mathrm{NMR}\left(\mathrm{CDCl}_{3}\right) \delta 0.87(\mathrm{t}$, $\left.3 \mathrm{H}, J=7.3 \mathrm{~Hz}, \mathrm{CH}_{3}\right) ; 1.25-1.43\left(\mathrm{~m}, 2 \mathrm{H}, \mathrm{CH}_{2}\right) ; 1.39$ (t, 3H, $\left.J=7.1 \mathrm{~Hz}, \mathrm{CH}_{3}\right) ; 1.60-1.70(\mathrm{~m}, 2 \mathrm{H}$, $\left.\mathrm{CH}_{2}\right) ; 2.62\left(\mathrm{t}, 2 \mathrm{H}, J=7.6 \mathrm{~Hz}, \mathrm{CH}_{2}\right) ; 4.36\left(\mathrm{q}, 2 \mathrm{H}, J=7.1 \mathrm{~Hz}, \mathrm{CH}_{2}\right) ; 5.58\left(\mathrm{~s}, 2 \mathrm{H}, \mathrm{CH}_{2} \mathrm{~N}\right) ; 7.07$ (d, $2 \mathrm{H}, J=7.8 \mathrm{~Hz}, \mathrm{AA}^{\prime} \mathrm{XX}$ '); 7.72 (d, 2H, $\left.J=8.5 \mathrm{~Hz}, \mathrm{AA}^{\prime} \mathrm{XX}^{\prime}\right)$; 7.82 (d, 2H, $\left.J=7.8 \mathrm{~Hz}, \mathrm{AA}^{\prime} \mathrm{XX}^{\prime}\right)$; $8.02\left(\mathrm{~d}, 2 \mathrm{H}, J=8.5 \mathrm{~Hz}, \mathrm{AA}^{\prime} X^{\prime} X^{\prime}\right) ; 8.25 \mathrm{ppm}$ (br s, $\left.1 \mathrm{H}, \mathrm{NH}\right)$. Anal. Calcd for $\mathrm{C}_{25} \mathrm{H}_{26} \mathrm{ClN}_{3} \mathrm{O}_{5}$ : C 62.05; H 5.38; N 8.69; Found: C 61.81; H 5.23; N 8.65.

Ethyl-2-\{[3-((2-butyl-4-chloro-5-carboxy-1H-imidazolyl)methyl)benzoyl]amino\}benzoate (20a). (133 mg, $0.27 \mathrm{mmol}, 43 \%$ yield) from 16a: mp 137-139 ${ }^{\circ} \mathrm{C} ;{ }^{1} \mathrm{H} \mathrm{NMR}\left(\mathrm{CDCl}_{3}\right) \delta 0.85(\mathrm{t}$, $\left.3 \mathrm{H}, J=7.1 \mathrm{~Hz}, \mathrm{CH}_{3}\right) ; 1.27-1.45\left(\mathrm{~m}, 2 \mathrm{H}, \mathrm{CH}_{2}\right) ; 1.41\left(\mathrm{t}, 3 \mathrm{H}, J=7.1 \mathrm{~Hz}, \mathrm{CH}_{3}\right) ; 1.59-1.72(\mathrm{~m}, 2 \mathrm{H}$, $\mathrm{CH}_{2}$ ); 2.65 (t, $\left.2 \mathrm{H}, J=7.5 \mathrm{~Hz}, \mathrm{CH}_{2}\right) ; 4.43$ (q, 2H, $\left.J=7.1 \mathrm{~Hz}, \mathrm{CH}_{2}\right) ; 5.63\left(\mathrm{~s}, 2 \mathrm{H}, \mathrm{CH}_{2} \mathrm{~N}\right) ; 7.08-$ $7.25(\mathrm{~m}, 2 \mathrm{H}, \mathrm{Ar}) ; 7.48(\mathrm{t}, 1 \mathrm{H}, J=7.9 \mathrm{~Hz}, \mathrm{Ar}) ; 7.58-7.60(\mathrm{~m}, 1 \mathrm{H}, \mathrm{Ar}) ; 7.73(\mathrm{~d}, 1 \mathrm{H}, J=1.6 \mathrm{~Hz}$, Ar); $7.96(\mathrm{~d}, 1 \mathrm{H}, J=7.9 \mathrm{~Hz}, \mathrm{Ar}) ; 8.08$ (dd, 1H, $J=1.6,8.0 \mathrm{~Hz}, \mathrm{Ar}) ; 8.88$ (d, 1H, $J=8.6 \mathrm{~Hz}, \mathrm{Ar})$; 12.11 ppm (br s, $1 \mathrm{H}, \mathrm{NH}$ ). Anal. Calcd for $\mathrm{C}_{25} \mathrm{H}_{26} \mathrm{ClN}_{3} \mathrm{O}_{5}$ : C 62.05; H 5.38; N 8.69; Found: C $61.93 ; \mathrm{H} 5.24 ; \mathrm{N} 8.52$.

Ethyl-3-\{[3-((2-butyl-4-chloro-5-carboxy-1H-imidazolyl)methyl)benzoyl]amino\}benzoate (20b). (195 mg, $0.40 \mathrm{mmol}, 63 \%$ yield) from 16b: ${ }^{1} \mathrm{H} \mathrm{NMR}\left(\mathrm{CDCl}_{3}\right) \delta 0.87(\mathrm{t}, 3 \mathrm{H}, J=7.1 \mathrm{~Hz}$, $\left.\mathrm{CH}_{3}\right)$; 1.25-1.42 (m, 2H, CH$) ; 1.38\left(\mathrm{t}, 3 \mathrm{H}, J=7.1 \mathrm{~Hz}, \mathrm{CH}_{3}\right) ; 1.59-1.72\left(\mathrm{~m}, 2 \mathrm{H}, \mathrm{CH}_{2}\right) ; 2.63(\mathrm{t}$, $\left.2 \mathrm{H}, J=7.5 \mathrm{~Hz}, \mathrm{CH}_{2}\right) ; 4.36$ (q, 2H, $\left.J=7.1 \mathrm{~Hz}, \mathrm{CH}_{2}\right) ; 5.56\left(\mathrm{~s}, 2 \mathrm{H}, \mathrm{CH}_{2} \mathrm{~N}\right) ; 7.05(\mathrm{~d}, 1 \mathrm{H}, J=7.1$ $\mathrm{Hz}, \mathrm{Ar})$; 7.35-7.47 (m, 2H, Ar); 7.68-7.83 (m, 3H, Ar); 7.94-8.11 (m, 2H, Ar); 8.24 ppm (br s, $1 \mathrm{H}, \mathrm{NH}$ ). Anal. Calcd for $\mathrm{C}_{25} \mathrm{H}_{26} \mathrm{ClN}_{3} \mathrm{O}_{5}$ : C 62.05; H 5.38; N 8.69; Found: C 62.40; H 5.27; N 8.67 .

Ethyl-4-\{[3-((2-butyl-4-chloro-5-carboxy-1H-imidazolyl)methyl)benzoyl]amino\}benzoate (20c). (174 mg, $0.36 \mathrm{mmol}, 56 \%$ yield) from 16c: $\mathrm{mp} 85-90{ }^{\circ} \mathrm{C} ;{ }^{1} \mathrm{H} \mathrm{NMR}\left(\mathrm{CDCl}_{3}\right) \delta 0.88(\mathrm{t}, 3 \mathrm{H}$, $\left.J=7.3 \mathrm{~Hz}, \mathrm{CH}_{3}\right) ; 1.22-1.44\left(\mathrm{~m}, 2 \mathrm{H}, \mathrm{CH}_{2}\right) ; 1.40\left(\mathrm{t}, 3 \mathrm{H}, J=7.1 \mathrm{~Hz}, \mathrm{CH}_{3}\right) ; 1.62-1.73(\mathrm{~m}, 2 \mathrm{H}$, $\left.\mathrm{CH}_{2}\right) ; 2.65$ (t, 2H, J=7.8 Hz, $\left.\mathrm{CH}_{2}\right) ; 4.38\left(\mathrm{q}, 2 \mathrm{H}, J=7.1 \mathrm{~Hz}, \mathrm{CH}_{2}\right) ; 5.57\left(\mathrm{~s}, 2 \mathrm{H}, \mathrm{CH}_{2} \mathrm{~N}\right) ; 7.08$ (d, $1 \mathrm{H}, J=7.2 \mathrm{~Hz}, \mathrm{Ar}) ; 7.42$ (t, 1H, $J=7.2 \mathrm{~Hz}, \mathrm{Ar}) ; 7.66-7.78$ (m, 4H, Ar); 8.04 (d, 2H, $J=7.3 \mathrm{~Hz}$, Ar); 8.20 ppm (br s, $1 \mathrm{H}, \mathrm{NH}$ ). Anal. Calcd for $\mathrm{C}_{25} \mathrm{H}_{26} \mathrm{ClN}_{3} \mathrm{O}_{5}$ : C 62.05; $\mathrm{H}$ 5.38; N 8.69; Found: C 61.86; H 5.50; N 8.70.

\section{General procedure for the preparation of compounds $17 \mathrm{a}-\mathrm{c}, 18 \mathrm{a}-\mathrm{c}$}

Sodium borohydride $(8.4 \mathrm{mg} ; 0.22 \mathrm{mmol}$ ) was added to a solution of the opportune aldehyde 15a-c, 16a-c $(0.36 \mathrm{~g} ; 0.75 \mathrm{mmol})$ in $\mathrm{MeOH}(1.60 \mathrm{~mL})$ cooled to $-10^{\circ} \mathrm{C}$. The resulting solution was stirred at $-10^{\circ} \mathrm{C}$ for $30 \mathrm{~min}$. and then was allowed to warm to room temperature. After 30 min. the mixture was quenched by addition of $50 \% \mathrm{CH}_{3} \mathrm{COOH}(0.03 \mathrm{~mL})$ and the resulting emulsion was extracted with AcOEt. The organic layer was washed with $\mathrm{H}_{2} \mathrm{O}$, dried and evaporated to give crude product $17 \mathbf{a}-\mathbf{c}, 18 \mathbf{a}-\mathbf{c}$

\section{Ethyl-2-\{[4-((2-butyl-4-chloro-5-hydroxymethyl-1 $\boldsymbol{H}$-imidazolyl)methyl)benzoyl $]$ amino $\}$}

benzoate (17a). Purified by column chromatography eluting with AcOEt $/ n$-hexane (8:2) afforded 17a (317 mg, $0.67 \mathrm{mmol}$, yield $90 \%$ ) from 15a: ${ }^{1} \mathrm{H}$ NMR $\left(\mathrm{CDCl}_{3}\right) \delta 0.85(\mathrm{t}, 3 \mathrm{H}, J=7.1$ 
$\left.\mathrm{Hz}, \mathrm{CH}_{3}\right) ; 1.21-1.33\left(\mathrm{~m}, 2 \mathrm{H}, \mathrm{CH}_{2}\right) ; 1.42\left(\mathrm{t}, 3 \mathrm{H}, J=7.1 \mathrm{~Hz}, \mathrm{CH}_{3}\right) ; 1.55-1.71\left(\mathrm{~m}, 2 \mathrm{H}, \mathrm{CH}_{2}\right) ; 2.54$ (t, $\left.2 \mathrm{H}, J=7.7 \mathrm{~Hz}, \mathrm{CH}_{2}\right) ; 4.40$ (q, 2H, $\left.J=7.1 \mathrm{~Hz}, \mathrm{CH}_{2}\right) ; 4.49$ (s, 2H, $\left.\mathrm{CH}_{2} \mathrm{OH}\right) ; 5.29$ (s, 2H, $\mathrm{CH}_{2} \mathrm{~N}$ ); 7.08-7.15 (m, 1H, Ar); 7.13 (d, 2H, $J=8.2 \mathrm{~Hz}, \mathrm{AA}^{\prime} \mathrm{XX}^{\prime}$ ); 7.56-7.60 (m, 1H, Ar); 8.00 (d, 2H, $\left.J=8.2 \mathrm{~Hz}, \mathrm{AA}^{\prime} \mathrm{XX}^{\prime}\right)$ ) 8.07-8.12 (m, 1H, Ar); 8.89 (d, 1H, $\left.J=8.4 \mathrm{~Hz}, \mathrm{Ar}\right) ; 12.13 \mathrm{ppm}(\mathrm{br}$ s, $1 \mathrm{H}, \mathrm{NH})$. MS m/z: $470\left(\mathrm{M}^{+}, 8\right)$. Anal. Calcd for $\mathrm{C}_{25} \mathrm{H}_{28} \mathrm{ClN}_{3} \mathrm{O}_{4}$ : C 63.96; H 5.96; N 8.94; Found: C 63.58; H 6.09; N 9.00.

\section{Ethyl-3-\{[4-((2-butyl-4-chloro-5-hydroxymethyl-1H-imidazolyl)methyl)benzoyl]amino\}}

benzoate (17b). Purified by crystallization from AcOEt/n-hexane (169 mg, $0.36 \mathrm{mmol}$, yield 48 \%) from 15b: ${ }^{1} \mathrm{H}$ NMR $\left(\mathrm{CDCl}_{3}\right) \delta 0.83\left(\mathrm{t}, 3 \mathrm{H}, J=7.1 \mathrm{~Hz}, \mathrm{CH}_{3}\right) ; 1.20-1.31\left(\mathrm{~m}, 2 \mathrm{H}, \mathrm{CH}_{2}\right) ; 1.38(\mathrm{t}$, $\left.3 \mathrm{H}, J=7.1 \mathrm{~Hz}, \mathrm{CH}_{3}\right) ; 1.53-1.72\left(\mathrm{~m}, 2 \mathrm{H}, \mathrm{CH}_{2}\right) ; 2.50\left(\mathrm{t}, 2 \mathrm{H}, J=7.7 \mathrm{~Hz}, \mathrm{CH}_{2}\right) ; 4.40$ (q, $2 \mathrm{H}, J=7.1$ $\left.\mathrm{Hz}, \mathrm{CH}_{2}\right) ; 4.49$ (s, 2H, $\left.\mathrm{CH}_{2} \mathrm{OH}\right) ; 5.27\left(\mathrm{~s}, 2 \mathrm{H}, \mathrm{CH}_{2} \mathrm{~N}\right) ; 7.07$ (d, 2H, J=7.8 Hz, Ar); 7.43 (t, 1H, $=8.1 \mathrm{~Hz}, \mathrm{Ar}) ; 7.80-7.90(\mathrm{~m}, 3 \mathrm{H}, \mathrm{Ar}) ; 8.05(\mathrm{~d}, 1 \mathrm{H}, J=8.1 \mathrm{~Hz}, \mathrm{Ar}) ; 8.12$ (s, 1H, Ar); $8.37 \mathrm{ppm}(\mathrm{br}$ s, $1 \mathrm{H}, \mathrm{NH})$. MS m/z: $470\left(\mathrm{M}^{+}, 10\right)$. Anal. Calcd for $\mathrm{C}_{25} \mathrm{H}_{28} \mathrm{ClN}_{3} \mathrm{O}_{4}$ : C 63.96; H 5.96; N 8.94; Found: C 63.76; H 5.96; N 9.13.

Ethyl-4-\{[4-((2-butyl-4-chloro-5-hydroxymethyl-1 $\boldsymbol{H}$-imidazolyl)methyl)benzoyl]amino\} benzoate (17c). Purified by crystallization from AcOEt/n-hexane to give 17c (183 mg, 0.39 mmol, $52 \%$ ) from 15c: ${ }^{1} \mathrm{H}$ NMR $\left(\mathrm{CDCl}_{3}\right) \delta 0.86\left(\mathrm{t}, 3 \mathrm{H}, J=7.2 \mathrm{~Hz}, \mathrm{CH}_{3}\right) ; 1.22-1.36(\mathrm{~m}, 2 \mathrm{H}$, $\left.\mathrm{CH}_{2}\right) ; 1.40\left(\mathrm{t}, 3 \mathrm{H}, J=7.1 \mathrm{~Hz}, \mathrm{CH}_{3}\right) ; 1.65-1.73\left(\mathrm{~m}, 2 \mathrm{H}, \mathrm{CH}_{2}\right) ; 2.53\left(\mathrm{t}, 2 \mathrm{H}, J=7.1 \mathrm{~Hz}, \mathrm{CH}_{2}\right) ; 4.37$ $\left(\mathrm{q}, 2 \mathrm{H}, J=7.1 \mathrm{~Hz}, \mathrm{CH}_{2}\right) ; 4.51\left(\mathrm{~s}, 2 \mathrm{H}, \mathrm{CH}_{2} \mathrm{OH}\right) ; 5.29\left(\mathrm{~s}, 2 \mathrm{H}, \mathrm{CH}_{2} \mathrm{~N}\right) ; 7.11(\mathrm{~d}, 2 \mathrm{H}, J=8.2 \mathrm{~Hz}$, $\mathrm{AA}^{\prime} \mathrm{XX}$ ); 7.73 (d, 2H, $\left.J=8.7 \mathrm{~Hz}, \mathrm{AA}^{\prime} \mathrm{XX}^{\prime}\right) ; 7.86$ (d, 2H, $\left.J=8.7 \mathrm{~Hz}, \mathrm{AA}^{\prime} \mathrm{XX}^{\prime}\right)$ ); 8.06 ppm (d, $\left.2 \mathrm{H}, J=8.2 \mathrm{~Hz}, \mathrm{AA}^{\prime} \mathrm{XX} X^{\prime}\right)$. MS $m / z$ : $470\left(\mathrm{M}^{+}, 15\right)$. Anal. Calcd for $\mathrm{C}_{25} \mathrm{H}_{28} \mathrm{ClN}_{3} \mathrm{O}_{4}: \mathrm{C} 63.96 ; \mathrm{H}$ 5.96; N 8.94; Found: C 64.24; H 5.75; N 8.99.

\section{Ethyl-2-\{[3-((2-butyl-4-chloro-5-hydroxymethyl-1 $H$-imidazolyl)methyl)benzoyl]amino $\}$} benzoate (18a). Purified by crystallization from AcOEt/n-hexane (144 mg, $0.31 \mathrm{mmol}$, yield 41 \%) from 16a: mp 89-91 ${ }^{\circ} \mathrm{C}$; IR: $1670\left(\mathrm{C}=\mathrm{O}\right.$ of ester); $1600\left(\mathrm{C}=\mathrm{O}\right.$ of amide) $\mathrm{cm}^{-1} .{ }^{1} \mathrm{HNMR}$ $\left(\mathrm{CDCl}_{3}\right) \delta 0.83\left(\mathrm{t}, 3 \mathrm{H}, J=7.3 \mathrm{~Hz}, \mathrm{CH}_{3}\right) ; 1.20-1.35\left(\mathrm{~m}, 2 \mathrm{H}, \mathrm{CH}_{2}\right) ; 1.46\left(\mathrm{t}, 3 \mathrm{H}, J=7.1 \mathrm{~Hz}, \mathrm{CH}_{3}\right)$; 1.55-1.68 (m, 2H, $\left.\mathrm{CH}_{2}\right) ; 2.49\left(\mathrm{t}, 2 \mathrm{H}, J=7.9 \mathrm{~Hz}, \mathrm{CH}_{2}\right) ; 4.46\left(\mathrm{q}, 2 \mathrm{H}, J=7.1 \mathrm{~Hz}, \mathrm{CH}_{2}\right) ; 4.62$ (s, $\left.2 \mathrm{H}, \mathrm{CH}_{2} \mathrm{OH}\right) ; 5.29\left(\mathrm{~s}, 2 \mathrm{H}, \mathrm{CH}_{2} \mathrm{~N}\right) ; 7.13(\mathrm{t}, 1 \mathrm{H}, J=7.9 \mathrm{~Hz}, \mathrm{Ar}) ; 7.30$ (d, 1H, J= $\left.7.9 \mathrm{~Hz}, \mathrm{Ar}\right)$; 7.48-7.65 (m, 3H, Ar); 8.00 (d, 1H, $J=7.5 \mathrm{~Hz}, \mathrm{Ar}) ; 8.10$ (d, 1H, J=7.9 Hz, Ar); 8.90 (d, 1H, $J$ $=8.2 \mathrm{~Hz}, \mathrm{Ar}) ; 12.01 \mathrm{ppm}$ (br s, $1 \mathrm{H}, \mathrm{NH})$. MS m/z: $470\left(\mathrm{M}^{+}, 34\right)$. Anal. Calcd for $\mathrm{C}_{25} \mathrm{H}_{28} \mathrm{ClN}_{3} \mathrm{O}_{4}$ : C 63.96; H 5.96; N 8.94; Found: C 63.76; H 6.21; N 9.24.

\section{Ethyl-3-\{[3-((2-butyl-4-chloro-5-hydroxymethyl-1 $\boldsymbol{H}$-imidazolyl)methyl)benzoyl]amino\}} benzoate (18b). Purified by crystallization from AcOEt/n-hexane offered 18b (194 mg, 0.41 mmol, yield $55 \%$ ) from 16b: mp 102-104 ${ }^{\circ} \mathrm{C} ;{ }^{1} \mathrm{HNMR}\left(\mathrm{CDCl}_{3}\right) \delta 0.79\left(\mathrm{t}, 3 \mathrm{H}, J=7.3 \mathrm{~Hz}, \mathrm{CH}_{3}\right)$; 1.16-1.31 (m, 2H, $\left.\mathrm{CH}_{2}\right) ; 1.38\left(\mathrm{t}, 3 \mathrm{H}, J=7.1 \mathrm{~Hz}, \mathrm{CH}_{3}\right) ; 1.46-1.64\left(\mathrm{~m}, 2 \mathrm{H}, \mathrm{CH}_{2}\right) ; 2.48(\mathrm{t}, 2 \mathrm{H}, J=$ $\left.7.3 \mathrm{~Hz}, \mathrm{CH}_{2}\right) ; 4.35$ (q, 2H, J=7.1 Hz, $\left.\mathrm{CH}_{2}\right) ; 4.51\left(\mathrm{~s}, 2 \mathrm{H}, \mathrm{CH}_{2} \mathrm{OH}\right) ; 5.23\left(\mathrm{~s}, 2 \mathrm{H}, \mathrm{CH}_{2} \mathrm{~N}\right) ; 7.16(\mathrm{~d}$, $1 \mathrm{H}, J=7.5 \mathrm{~Hz}, \mathrm{Ar}) ; 7.38-7.47$ (m, 2H, Ar); 7.74-7.86 (m, 3H, Ar); 8.01 (s, 1H, Ar); 8.08 (d, 1H, $J=8.4 \mathrm{~Hz}, \mathrm{Ar}) ; 8.88 \mathrm{ppm}(\mathrm{br} \mathrm{s}, 1 \mathrm{H}, \mathrm{NH})$. MS $m / z: 470\left(\mathrm{M}^{+}, 100\right)$. Anal. Calcd for $\mathrm{C}_{25} \mathrm{H}_{28} \mathrm{ClN}_{3} \mathrm{O}_{4}$ : C 63.96; H 5.96; N 8.94; Found: C 64.29; H 5.74; N 8.59. 
Ethyl-4-\{[3-((2-butyl-4-chloro-5-hydroxymethyl-1H-imidazolyl)methyl)benzoyl]amino\}

benzoate (18c). Purified by crystallization from AcOEt/n-hexane offered 18c (282 mg, 0.60 mmol, yield $80 \%$ ) from 16c: mp 45-47; ${ }^{1} \mathrm{H} \mathrm{NMR}\left(\mathrm{CDCl}_{3}\right) \delta 0.82\left(\mathrm{t}, 3 \mathrm{H}, J=7.1 \mathrm{~Hz}, \mathrm{CH}_{3}\right) ; 1.22-$ $1.42\left(\mathrm{~m}, 2 \mathrm{H}, \mathrm{CH}_{2}\right) ; 1.39$ (t, 3H, $\left.J=7.1 \mathrm{~Hz}, \mathrm{CH}_{3}\right) ; 1.54-1.62\left(\mathrm{~m}, 2 \mathrm{H}, \mathrm{CH}_{2}\right) ; 2.46-2.57$ (m, 2H, $\left.\mathrm{CH}_{2}\right) ; 4.36\left(\mathrm{q}, 2 \mathrm{H}, J=7.1 \mathrm{~Hz}, \mathrm{CH}_{2}\right) ; 4.51\left(\mathrm{~s}, 2 \mathrm{H}, \mathrm{CH}_{2} \mathrm{OH}\right) ; 5.21\left(\mathrm{~s}, 2 \mathrm{H}, \mathrm{CH}_{2} \mathrm{~N}\right) ; 7.14(\mathrm{~d}, 1 \mathrm{H}, J=$ 6.8 Hz, Ar); 7.39-7.50 (m, 2H, Ar); 7.69-7.81 (m, 3H, Ar); 7.99-8.02 ppm (m, 2H, Ar). MS m/z: $470\left(\mathrm{M}^{+}, 48\right)$. Anal. Calcd for $\mathrm{C}_{25} \mathrm{H}_{28} \mathrm{ClN}_{3} \mathrm{O}_{4}$ : C 63.96; H 5.96; N 8.94; Found: C 63.66; H 5.71; N 8.90.

General procedure for the preparation of compounds $22 \mathrm{a}-\mathrm{c}$ and $23 \mathrm{a}-\mathrm{c}$

To a solution of 3-(trifluoromethyl)- $1 H$-pyrazole 21 (85 mg; $0.63 \mathrm{mmol})$ in $\mathrm{CH}_{3} \mathrm{CN}(2.5 \mathrm{ml})$ were added compound 12a-c, 13a-c $(0.20 \mathrm{~g} ; 0.63 \mathrm{mmol}), \mathrm{K}_{2} \mathrm{CO}_{3}(0.13 \mathrm{~g} ; 0.94 \mathrm{mmol})$ e $\mathrm{KI}$ (13 $\mathrm{mg} ; 0.08 \mathrm{mmol}$ ) and the resulting suspension was refluxed for $5 \mathrm{~h}$. After this period the mixture was cooled to room temperature and was filtered. The solvent was evaporated to give $\mathbf{2 2 a - c}$ and 23a-c.

Ethyl-2-[(4-\{[3-(trifluoromethyl)-1H-pyrazolyl]methyl\}benzoyl)amino]benzoate (22a). (226 $\mathrm{mg}, 0.54 \mathrm{mmol}$, yield $86 \%$ ) from 12a: ${ }^{1} \mathrm{H} \mathrm{NMR}\left(\mathrm{CDCl}_{3}\right) \delta 1.26\left(\mathrm{t}, 3 \mathrm{H}, J=7.1 \mathrm{~Hz}, \mathrm{CH}_{3}\right) ; 4.40$ (q, $\left.2 \mathrm{H}, J=7.1 \mathrm{~Hz}, \mathrm{CH}_{2}\right) ; 5.44\left(\mathrm{~s}, 2 \mathrm{H}, \mathrm{CH}_{2} \mathrm{~N}\right) ; 6.58-6.62(\mathrm{~m}, 1 \mathrm{H}$, pyrazole); $7.13(\mathrm{t}, 1 \mathrm{H}, J=6.9$ $\mathrm{Hz}, \mathrm{Ar})$; 7.34-7.64 (m, 4H, Ar, pyrazole); 7.94-8.12 (m, 3H, Ar); 8.88-8.93 (m, 1H, Ar); 12.13 ppm (br s, $1 \mathrm{H}, \mathrm{NH}$ ). Anal. Calcd for $\mathrm{C}_{21} \mathrm{H}_{18} \mathrm{~F}_{3} \mathrm{~N}_{3} \mathrm{O}_{3}$ : C 60.43; H 4.30; N 10.07; Found: C 60.57; H 4.34; N 10.35.

Ethyl-3-[(4-\{[3-(trifluoromethyl)-1H-pyrazolyl]methyl\}benzoyl)amino]benzoate (22b). (236 mg, 0.57 mmol, yield $90 \%$ ) from 12b: ${ }^{1} \mathrm{H} \mathrm{NMR}\left(\mathrm{CDCl}_{3}\right) \delta 1.39\left(\mathrm{t}, 3 \mathrm{H}, J=7.1 \mathrm{~Hz}, \mathrm{CH}_{3}\right) ; 4.37$ (q, $\left.2 \mathrm{H}, J=7.1 \mathrm{~Hz}, \mathrm{CH}_{2}\right) ; 5.43\left(\mathrm{~s}, 2 \mathrm{H}, \mathrm{CH}_{2} \mathrm{~N}\right) ; 6.58(\mathrm{~d}, 1 \mathrm{H}, J=2.4 \mathrm{~Hz}$, pyrazole); 7.33 (d, 2H, $J=$ 8.2 Hz, Ar); 7.41-7.54 (m, 1H, Ar); 7.62-7.66 (m, 1H, pyrazole); 7.81-7.90 (m, 3H, Ar); 7.998.10 ppm (m, 2H, Ar). Anal. Calcd for $\mathrm{C}_{21} \mathrm{H}_{18} \mathrm{~F}_{3} \mathrm{~N}_{3} \mathrm{O}_{3}$ : C 60.43; H 4.30; N 10.07; Found: C 60.23; H 4.16; N 10.10.

Ethyl-4-[(4-\{[3-(trifluoromethyl)-1 H-pyrazolyl]methyl\}benzoyl)amino]benzoate

(22c). Purified by precipitation from $\mathrm{Et}_{2} \mathrm{O} / \mathrm{n}$-hexane offered 22c (123 mg, $0.30 \mathrm{mmol}$, yield $\left.47 \%\right)$ from 12c: IR: $1697\left(\mathrm{C}=\mathrm{O}\right.$ of ester); $1649\left(\mathrm{C}=\mathrm{O}\right.$ of amide) $\mathrm{cm}^{-1} .{ }^{1} \mathrm{H}$ NMR $\left(\mathrm{CDCl}_{3}\right) \delta 1.40(\mathrm{t}, 3 \mathrm{H}, J=7.1$ $\left.\mathrm{Hz}, \mathrm{CH}_{3}\right) ; 4.37$ (q, 2H, $\left.J=7.1 \mathrm{~Hz}, \mathrm{CH}_{2}\right) ; 5.44\left(\mathrm{~s}, 2 \mathrm{H}, \mathrm{CH}_{2}\right) ; 6.58$ (d, 1H, $J=2.5 \mathrm{~Hz}$, pyrazole); $7.35\left(\mathrm{~d}, 2 \mathrm{H}, J=8.2 \mathrm{~Hz}, \mathrm{AA}^{\prime} \mathrm{XX} \mathrm{X}^{\prime}\right) ; 7.44-7.46(\mathrm{~m}, 1 \mathrm{H}$, pyrazole); $7.72(\mathrm{~d}, 2 \mathrm{H}, J=8.7 \mathrm{~Hz}$, $\mathrm{AA}^{\prime} \mathrm{XX}$ '); 7.87 (d, 2H, $J=8.2 \mathrm{~Hz}, \mathrm{AA}^{\prime} \mathrm{XX}$ '); $8.06 \mathrm{ppm}\left(\mathrm{d}, 2 \mathrm{H}, J=8.7 \mathrm{~Hz}, \mathrm{AA}^{\prime} \mathrm{XX}^{\prime}\right)$. Anal. Calcd for $\mathrm{C}_{21} \mathrm{H}_{18} \mathrm{~F}_{3} \mathrm{~N}_{3} \mathrm{O}_{3}$ : C 60.43; H 4.30; N 10.07; Found: C 60.01; H 4.17; N 9.90.

Ethyl-2-[(3-\{[3-(trifluoromethyl)-1H-pyrazolyl]methyl\}benzoyl)amino]benzoate (23a). (254 mg, $0.61 \mathrm{mmol}$, yield $97 \%$ ) from 13a: mp 88-90; ${ }^{1} \mathrm{H} \mathrm{NMR}\left(\mathrm{CDCl}_{3}\right) \delta 1.43(\mathrm{t}, 3 \mathrm{H}, J=7.1 \mathrm{~Hz}$, $\left.\mathrm{CH}_{3}\right) ; 4.42$ (q, $\left.2 \mathrm{H}, J=7.1 \mathrm{~Hz}, \mathrm{CH}_{2}\right) ; 5.46\left(\mathrm{~s}, 2 \mathrm{H}, \mathrm{CH}_{2} \mathrm{~N}\right) ; 6.55-6.60$ (m, 1H, pyrazole); 7.10-7.17 (m, 1H, Ar); 7.39-7.64 (m, 4H, Ar, pyrazole); 7.96-8.02 (m, 2H, Ar); 8.10 (d, 1H, J = 7.5 Hz, Ar); 8.90 (d, 1H, $J=8.4 \mathrm{~Hz}, \mathrm{Ar}) ; 12.13$ ppm (br s, $1 \mathrm{H}, \mathrm{NH})$. MS m/z: $417\left(\mathrm{M}^{+}, 3\right)$. Anal. Calcd for $\mathrm{C}_{21} \mathrm{H}_{18} \mathrm{~F}_{3} \mathrm{~N}_{3} \mathrm{O}_{3}$ : C 60.43; H 4.30; N 10.07; Found: C 60.13; H 4.54; N 10.32. 
Ethyl-3-[(3-\{[3-(trifluoromethyl)-1H-pyrazolyl]methyl\} benzoyl)amino]benzoate (23b). (165 mg, 0.40 mmol, yield $63 \%$ ) from 13b: mp 130-132 ${ }^{\circ} \mathrm{C} ;{ }^{1} \mathrm{H} \mathrm{NMR}\left(\mathrm{CDCl}_{3}\right) \delta 1.40(\mathrm{t}, 3 \mathrm{H}, J=7.1$ $\left.\mathrm{Hz}, \mathrm{CH}_{3}\right) ; 4.38\left(\mathrm{q}, 2 \mathrm{H}, J=7.1 \mathrm{~Hz}, \mathrm{CH}_{2}\right) ; 5.42\left(\mathrm{~s}, 2 \mathrm{H}, \mathrm{CH}_{2} \mathrm{~N}\right) ; 6.55-6.58(\mathrm{~m}, 1 \mathrm{H}$, pyrazole); 7.397.54 (m, 3H, Ar, pyrazole); 7.80-7.86 (m, 3H, Ar); 7.96 (s, 1H, Ar); 8.02-8.10 ppm (m, 2H, Ar); MS m/z: $417\left(\mathrm{M}^{+}, 33\right)$. Anal. Calcd for $\mathrm{C}_{21} \mathrm{H}_{18} \mathrm{~F}_{3} \mathrm{~N}_{3} \mathrm{O}_{3}: \mathrm{C}$ 60.43; H 4.30; $\mathrm{N} \mathrm{10.07;} \mathrm{Found:} \mathrm{C}$ $60.69 ; \mathrm{H} 4.43$; N 10.28.

Ethyl-4-[(3-\{[3-(trifluoromethyl)-1H-pyrazolyl]methyl $\}$ benzoyl)amino]benzoate (23c). (250 mg, 0.60 mmol, yield $95 \%$ from 13c: mp 63-65; ${ }^{1} \mathrm{H}$ NMR $\left(\mathrm{CDCl}_{3}\right) \delta 1.40(\mathrm{t}, 3 \mathrm{H}, J=7.1 \mathrm{~Hz}$, $\left.\mathrm{CH}_{3}\right) ; 4.37$ (q, 2H, $\left.J=7.1 \mathrm{~Hz}, \mathrm{CH}_{2}\right) ; 5.40\left(\mathrm{~s}, 2 \mathrm{H}, \mathrm{CH}_{2} \mathrm{~N}\right) ; 6.56-6.60(\mathrm{~m}, 1 \mathrm{H}$, pyrazole); 7.37-7.50 (m, 2H, Ar, pyrazole); 7.64-7.83 (m, 2H, Ar); 7.73 (d, 2H, $\left.J=8.6 \mathrm{~Hz}, \mathrm{AA}^{\prime} \mathrm{XX}^{\prime}\right)$; 8.04 (d, 2H, $J=$ $8.6 \mathrm{~Hz}, \mathrm{AA}^{\prime} \mathrm{XX}$ '); $8.22 \mathrm{ppm}(\mathrm{s}, 1 \mathrm{H}, \mathrm{Ar})$. MS m/z: $417\left(\mathrm{M}^{+}, 11\right)$. Anal. Calcd for $\mathrm{C}_{21} \mathrm{H}_{18} \mathrm{~F}_{3} \mathrm{~N}_{3} \mathrm{O}_{3}$ : C 60.43; H 4.30; N 10.07; Found: C 60.50; H 4.71; N 10.39.

\section{Angiotensin II receptor binding assay}

Male Wistar rats were killed by decapitation, and their livers were rapidly removed. Rat liver membranes were prepared by differential centrifugation, as previously described. ${ }^{13}$ Briefly, liver was dissected free of fatty tissue and minced accurately with small scissors, and then about $3 \mathrm{~g}$ of tissue was homogenized by Polytron Ultra-Turrax (maximal speed for 2 x 30s) in ice cold 20 vol of Tris- $\mathrm{HCl} 5 \mathrm{mM}$, sucrose $0.25 \mathrm{M}(\mathrm{pH} 7.4)$. The homogenate was centrifuged at $750 \mathrm{~g}$ for 10 min at $4{ }^{\circ} \mathrm{C}$ and the supernatant was filtered through cheesecloth and saved. The pellets were homogenized and centrifuged as before. The combined supernatants were centrifuged at $48,000 \mathrm{~g}$ for $15 \mathrm{~min}$ at $4{ }^{\circ} \mathrm{C}$. The resulting pellet was resuspended in Tris- $\mathrm{HCl} 5 \mathrm{mM}$, sucrose $0.25 \mathrm{M}(\mathrm{pH}$ 7.4), and centrifuged as above. The final pellets were used immediately or stored frozen at -70 ${ }^{\circ} \mathrm{C}$ before use. The membrane pellet were resuspended in Tris- $\mathrm{HCl} 50 \mathrm{mM}, \mathrm{NaCl} 100 \mathrm{mM}$, $\mathrm{MgCl}_{2} 10 \mathrm{mM}$, EDTA $1 \mathrm{mM}$, bacitracin $100 \mu \mathrm{M}$, PMSF $100 \mu \mathrm{M}$, BSA $0.1 \%$ (pH 7.4) to obtain a final protein concentration of $2.5 \mathrm{mg} / \mathrm{mL}$. Angiotensin II binding assay was performed incubating aliquots of liver membranes $(50 \mu \mathrm{g})$ at $25^{\circ} \mathrm{C}$ for $180 \mathrm{~min}$ in $100 \mu \mathrm{L}$ assay buffer conteining 25 pM [ $\left.{ }^{125} \mathrm{I}\right] \mathrm{Sar}^{1}{ }^{,} \mathrm{Ile}^{8}$-angiotensin II (Perkin Elmer life Sciences). Non specific binding was measured in the presence of $1 \mu \mathrm{M}$ angiotensin II and represented 5-10\% of total binding.

Binding was terminated by rapid vacuum filtration using $\mathrm{GF} / \mathrm{G}$ glass fiber filters performing three washes with $4 \mathrm{~mL}$ of ice cold $\mathrm{NaCl} 100 \mathrm{mM}, \mathrm{MgCl}_{2} 100 \mathrm{mM}$ buffer. Dried filters disks were counted in a gamma-counter with $92 \%$ efficiency. The compound $\%$ inhibition values were estimated at $10 \mu \mathrm{M}$ concentration. For all tested compounds $\mathrm{IC}_{50}$ values were not calculable.

\section{Molecular modeling}

The ligands were docked in our recently published AT1 model The ligands were submitted to a conformational search of 1000 steps with an energy window for saving structure of $10 \mathrm{KJ} / \mathrm{mol}$. The algorithm used was the Montecarlo method with MMFFs as the forcefield and a distancedependent dielectric constant of 1.0. The ligands were then minimized using the Conjugated Gradient method until a convergence value of $0.05 \mathrm{kcal} / \AA ̊ \mathrm{~mol}$, using the same forcefield and dielectric constant used for the conformational search. ${ }^{14}$ Then the ligands were docked into the 
receptor using the AUTODOCK 3.0 program. ${ }^{15}$ The regions of interest used by AUTODOCK were defined by considering atom CZ3 of W6.48(253) as the central residue of a grid of 50, 44, and 48 points in the $x, y$, and $z$ directions. A grid spacing of $0.375 \AA$ and a distance-dependent function of the dielectric constant were used for the energetic map calculations.

Using the Lamarckian Genetic Algorithm, the compounds were subjected to 100 runs of the AUTODOCK search, in which the default values of the other parameters were used. Cluster analysis was performed on the docked results using an RMS tolerance of $1.0 \AA$.

\section{Acknowledgements}

We thank the MIUR (Italian Ministry of Schooling, Higher Education and Research) for partial support of this project through a grant.

\section{References}

1. Meier, P.; Maillard M.; Burnier, M. Current Drug Targets - Cardiovascular \& Haematological Disorders 2005, 5, 15.

2. Unger, T.; Badoer, E.; Ganten, D.; Lang, R. E.; Rettig, R. Circulation 1988, 77, 140.

3. Juillerat-Jeanneret, L.; Celerier, J.; Chapuis Bernasconi, C.; Nguyen, G.; Wostl, W.; Maerki, H. P.; Janzer, R. C.; Corvol, P.; Gasc, J. M. Br. J. Cancer 2004, 90, 1059.

4. Fogarty, D. J.; Sanchez-Gomez, M. V.; Matute, C. Glia 2002, 39, 304.

5. Weber, M. A. JRAAS 2003, 4, 62.

6. Manohar, P.; Pina, I. L. Mayo Clin. Proc. 2003, 78, 334.

7. Norris, K.; Vaughn, C. Exp. ReV. CardioVasc. Ther. 2003, 1, 51.

8. Ashton, W. T.; Hutchins, S. M.; Greenlee, W. J.; Doss, G. A.; Chang, R. S.; Lotti, V. J.; Faust, K. A.; Chen, T. B.; Zingaro, G. J.; Kivlighn, S. D. J . Med. Chem. 1993, 36, 3595.

9. Duncia, J. V.; Chiu, A. T.; Carini, D. J.; Gregory, G. B.; Johnson, A. L.; Price, W. A.; Wells, G. J.; Wong, P. C.; Calabrese, J. C.; Timmermans, P. B. M. W. M. J. Med. Chem. 1990, 33, 1312 .

10. Larsen, R. D.; King, A. O.; Chen, C. Y.; Corley, E. G.; Foster, B. S.; Roberts, F. E.; Yang, C.; Lieberman, D. R.; Reamer, R. A.; Tschaen, D. M.; Verhoeven, T. R.; Reider, P. J.; Lo, Y. S.; Rossano, L. T.; Brookes, A. S.; Meloni, D.; Moore, J. R.; Arnett, J. F. J. Org. Chem. 1994, 59, 6391.

11. Tuccinardi, T.; Calderone, V.; Rapposelli, S.; Martinelli, A. J. Med. Chem. 2006, 49, 4305.

12. Tuccinardi, T.; Martinelli, A. Curr. Med. Chem. 2007, 14, 3105.

13. Cappelli, A.; Pericot, M.G.; Gallelli, A.; Rizzo, M.; Anzini, M.; Vomero, S.; Mennuni, L.; Ferrari, F.; Makovec, F.; Menziani, M.C.; De Benedetti P.G.; Giorgi, G. J. Med. Chem. 2004, 47, 2574.

14. Macromodel ver. 8.5; Schrodinger Inc.: New York, 1999.

15. Morris, G. M.; Goodsell, D. S.; Halliday, R. S.; Huey, R.; Hart, W. E.; Belew, R. K.; Olson, A. J. J. Comp. Chem. 1998, 19, 1639. 